\title{
Unique actions of GABA arising from cytoplasmic chloride microdomains
}

Negah Rahmati ${ }^{1 *}$, Kieran P. Normoyle ${ }^{*}$, Joseph Glykys ${ }^{2}$, Volodymyr I. Dzhala ${ }^{1}$, Kyle P. Lillis ${ }^{1}$, Kristopher T. Kahle ${ }^{3}$, Rehan Raiyyani ${ }^{1}$, Theju Jacob ${ }^{1}$ and Kevin J. Staley ${ }^{1}$

1. Harvard Medical School and Massachusetts General Hospital, Department of Neurology, Boston, MA, USA

2. University of Iowa, Department of Pediatrics and Neurology, Iowa Neuroscience Institute, Carver College of Medicine, Iowa City, IA, USA

3. Yale School of Medicine, Departments of Neurosurgery, Pediatrics, and Cellular \& Molecular Physiology, New Haven, CT, USA

* These authors contributed equally to this work.

Correspondence: staley.kevin@mgh.harvard.edu

\begin{abstract}
:
Developmental, cellular, and subcellular variations in the direction of neuronal $\mathrm{Cl}^{-}$currents elicited by $\mathrm{GABA}_{\mathrm{A}}$ receptor activation have been frequently reported, and we found a corresponding variance in the reversal potential $\left(\mathrm{E}_{\mathrm{GABA}}\right)$ for individual interneurons synapsing on a single pyramidal cell. These findings suggest a corresponding variance in the cytoplasmic concentration of $\mathrm{Cl}^{-}\left(\left[\mathrm{Cl}^{-} \mathrm{i}\right]\right)$. We determined $\left[\mathrm{Cl}^{-}\right] \mathrm{i}$ by: 1) two-photon imaging of the $\mathrm{Cl}^{-}$sensitive, ratiometric fluorescent protein SuperClomeleon (sCLM); 2) Fluorescence Lifetime IMaging (FLIM) of the $\mathrm{Cl}^{-}$sensitive fluorophore MEQ; and 3) electrophysiological measurements of EGABA. These methods collectively demonstrated stable $\left[\mathrm{Cl}^{-}\right]_{\mathrm{i}}$ microdomains in individual neurons in vivo. Fluorometric and electrophysiological estimates of local $\left[\mathrm{Cl}^{-}\right]_{\mathrm{i}}$ were highly
\end{abstract}


correlated. $\left[\mathrm{Cl}^{-}\right]_{\mathrm{i}}$ microdomains persisted after pharmacological inhibition of cation-chloride cotransporters (CCCs) but steadily decreased after inhibiting the polymerization of the anionic macromolecule actin. These studies highlight the existence of functionally significant neuronal $\mathrm{Cl}^{-}$microdomains that modify the impact of GABAergic inputs.

\section{Introduction:}

The group-mean values of $\mathrm{E}_{\mathrm{GABA}}$ are continuously distributed over a $25 \mathrm{mV}$ range from -85 to $60 \mathrm{mV}$ in twenty recent studies utilizing gramicidin perforated patch recording techniques in CA1 pyramidal cells from rodents with mature neuronal $\mathrm{Cl}^{-}$transport (Romo-Parra et al., 2008; Tyzio et al., 2008) (Table S1). Over this wide range of reversal potentials, the effects of GABAA receptor-gated currents will vary from inhibition via hyperpolarization of the membrane potential, through shunting inhibition, to excitation mediated by activation of low-threshold calcium currents and partial relief of the magnesium block of NMDA receptors (Doyon et al., 2016). These divergent effects suggest that $\mathrm{E}_{\mathrm{GABA}}$ must be tightly regulated, although the mechanisms of regulation have not been resolved.

The observed range in EGABA could be explained by a few $\mathrm{mM}$ variation in the cytoplasmic concentration of $\mathrm{Cl}^{-}\left(\left[\mathrm{Cl}^{-}\right]\right.$), the anion with the highest permeability through GABAARs (Alfonsa et al., 2015b; Doyon et al., 2016; Raimondo et al., 2017). Such differences in $\left[\mathrm{Cl}^{-}\right]_{\mathrm{i}}$ could be maintained by the active transport of $\mathrm{Cl}^{-}$. For example, KCC2 and NKCC1 are oppositelydirected cation- $\mathrm{Cl}^{-}$cotransporters (CCCs) expressed in neurons (Kahle et al., 2015). However, these are high-velocity transporters whose ionic equilibrium conditions do not match well with the distribution of observed $\mathrm{E}_{\mathrm{GABA}}$ (Delpire and Staley, 2014), and inhibition of transport does not produce the predicted changes in $\left[\mathrm{Cl}^{-}\right]_{\mathrm{i}}$ (Glykys et al., 2014b; Sato et al., 2017).

Another possibility is suggested by the well-known partitioning effects on mobile ions exerted by the distribution of immobile ions (Fatin-Rouge et al., 2003) that for example create GibbsDonnan effects (Donnan, 1911) in gels (Procter, 1914) and unlinked biopolymers (Marinsky, 1985), and form the basis of ion exchange technologies (Yamamoto et al., 1988; Helfferich, 1995). Relatively immobile cytoplasmic biopolymers with high and spatially inhomogeneous 
densities of anionic charge, such as actin, tubulin, and nucleic acids (Gianazza and Righetti, 1980; Sanabria et al., 2006; Janke et al., 2008; Chen et al., 2020) could displace $\mathrm{Cl}^{-}$locally (Glykys et al., 2014b; Glykys et al., 2017). Recent studies have underscored substantial variance in the subcellular distribution of these anionic biopolymers (Koleske, 2013; Morawski et al., 2015; Gut et al., 2018; Chen et al., 2020), suggesting that if the displacement of $\mathrm{Cl}^{-}$underlies the intercellular diversity in $E_{G A B A}$, there should be a corresponding spatial variance in the subcellular distribution of $\mathrm{Cl}^{-}$. Indeed, many reports have suggested subcellular variance in $\left[\mathrm{Cl}^{-}\right]_{\mathrm{i}}$ or Egaba (Pouzat and Marty, 1999; Berglund et al., 2006; Duebel et al., 2006; Szabadics et al., 2006; Romo-Parra et al., 2008; Földy et al., 2010; Glykys et al., 2014b; Astorga et al., 2015; Untiet et al., 2016; Zorrilla de San Martin et al., 2017; Schmidt et al., 2018) for which several mechanisms have been proposed (Khirug et al., 2008; Földy et al., 2010; Glykys et al., 2014b).

We report a unique $E_{G A B A}$ for each response to individual interneurons, and demonstrate a corresponding variance in local neuronal $\left[\mathrm{Cl}^{-}\right]_{\mathrm{i}}$ in vivo and in vitro. Several complimentary techniques were employed including two-photon microscopy of the ratiometric $\mathrm{Cl}^{-}$indicator SuperClomelon (sCLM) (Grimley et al., 2013); Fluorescence Lifetime IMaging (FLIM) of $\mathrm{Cl}^{-}$sensitive, pH-insensitive dye 6-methoxy-N-ethylquinolinium (MEQ) (Biwersi and Verkman, 1991); and simultaneous direct measurement of the reversal potential of locally-activated

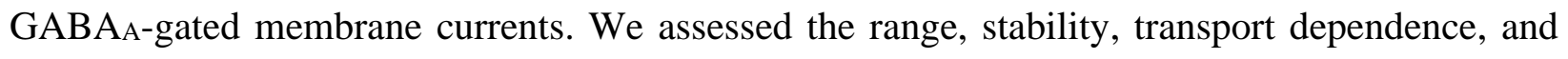
influence of anionic macromolecules on the observed variance in local baseline $\left[\mathrm{Cl}^{-}\right]_{\mathrm{i}}$.

\section{Results}

\section{Unique response of single pyramidal cells to individual inhibitory interneurons:}

We recorded single pyramidal cells using whole-cell patch clamping while selectively activating individual neighboring inhibitory interneurons (Figure 1A). We observed unique, reproducible values of $E_{G A B A}$ for each interneuron-pyramidal cell pair (Figure 1B) whose distribution paralleled the broad range of previously reported EGABA (Figure 1C and Table S1). Our results demonstrate that individual interneurons have unique $\mathrm{E}_{\mathrm{GABA}}$ on postsynaptic pyramidal cells $(\mathrm{n}=$ 40 cells, 10 experiments, $\sim 23 \mathrm{mV}$ range in $\left.\mathrm{E}_{\mathrm{GABA}}\right)$. The measured range may be an underestimate 
of the variance of synaptic $\mathrm{E}_{\mathrm{GABA}}$ in these neurons, because individual interneurons have on average 10 synapses onto pyramidal cells (Maccaferri et al., 2000; Bezaire and Soltesz, 2013), each of which may have a different $\mathrm{E}_{\mathrm{GABA}}$, and the somatic recording would reflect the combined currents from all synapses originating from the activated interneuron. Not all stimulated interneurons evoked GABAergic currents in the recorded pyramidal cells. Fifty six percent of the stimulated interneurons resulted in recordable currents.

\section{Evidence for dendritic chloride microdomains by fluorescence microscopy and electrophysiology:}

How can a single neuron express so many different values of EGABA? To investigate this, we measured the subcellular $\left[\mathrm{Cl}^{-}\right]_{\mathrm{i}}$ distribution in single neurons. To enable cell-type specific analysis of subcellular cytoplasmic $\mathrm{Cl}^{-}$concentrations, we designed a conditional SuperClomeleon $(s C L M)$ over-expression mouse line by generating a floxed stop/sCLM knock-in at the Rosa26 locus (Methods, Figure S1). sCLM is a recently-developed ratiometric $\mathrm{Cl}^{-}$ indicator with improved sensitivity compared to its predecessor Clomeleon (CLM) (Grimley et al., 2013). These fluorophores measure cytoplasmic $\mathrm{Cl}^{-}$in many neurons and subcellular locations at once, without the perturbations of the intracellular milieu induced by whole-cell and perforated patch clamping. DNA Sanger sequencing confirmed the presence of the knocked-in $s C L M$ allele (Methods, Figure S1). Both heterozygous and homozygous mice were viable and fertile and survived to adulthood without any abnormalities.

In vivo ratiometric two-photon fluorescence imaging was performed on anesthetized mice in which sCLM expression was driven by crosses with either CamKII or Dlx Cre mice to selectively express the fluorophore in principal cells or interneurons, respectively (see Methods). YFP/CFP values were compared in neurons of cortical layers II and III (Figure 2A). We analyzed the dendrites that were located at the same imaging depth (Figure 2B) to exclude the impact of depth-dependent differential scattering of cyan vs yellow light by the brain tissue (Boffi et al., 2018). The data are presented as YFP/CFP ratios rather than $\left[\mathrm{Cl}^{-}\right]_{\mathrm{i}}$ because calibration of sCLM is not feasible in vivo (Arosio and Ratto, 2014; Boffi et al., 2018). This is a consequence of limited capacity to permeabilize the membrane of target neurons and to 
manipulate the extracellular $\mathrm{Cl}^{-}$concentration (Krapf et al., 1988). However, our data demonstrate a clear variance in YFP/CFP ratios in dendrites and soma (Figure 2A and 2B).

To analyze the subcellular $\mathrm{Cl}^{-}$variance in a preparation in which sCLM YFP/CFP ratios can be quantitatively calibrated to $\left[\mathrm{Cl}^{-}\right]$, we performed two-photon high resolution fluorescence microscopy of hippocampal organotypic slice cultures expressing sCLM. Our data demonstrate spatial variability of $\left[\mathrm{Cl}^{-}\right]_{\mathrm{i}}$ in the dendrites of individual neurons in the presence of $1 \mu \mathrm{M}$ TTX (Figure 2C-2F). The individual pixels of the neuron depicted in panel $\mathrm{F}$ demonstrate a wide range in dendritic $\left[\mathrm{Cl}^{-}\right]_{\text {i }}$ (Figure 1G). To examine the contribution of noise to these images, we performed time series imaging of CLM-expressing neurons (180 images over 30 minutes). Fluorescence intensity arising from stable cytoplasmic $\left[\mathrm{Cl}^{-}\right]_{\mathrm{i}}$ microdomains would be expected to exhibit less temporal variance than noise. Over the 30-minute observation period, the spatiotemporal variation in dendritic YFP intensity was much less than the corresponding variance produced by noise (measured with the shutter closed and normalized to the YFP emission intensity) (Figure 2H and S2). This supports the presence of persistent spatial differences in $\left[\mathrm{Cl}^{-}\right.$ ]i that cannot be explained by noise.

sCLM retains the $\mathrm{pH}$ sensitivity of CLM (Grimley et al., 2013). To test whether the fluorescence measures of $\left[\mathrm{Cl}^{-}\right]_{\mathrm{i}}$ correlated with electrophysiological assays of $\left[\mathrm{Cl}^{-}\right]_{\mathrm{i}}$, simultaneous measurements of local dendritic $\left[\mathrm{Cl}^{-}\right]_{\mathrm{i}}$ by $\mathrm{sCLM}$ and direct calculation of $\mathrm{E}_{\mathrm{GABA}}$ by gramicidinperforated patch-clamp recording and local pressure application of $10 \mu \mathrm{M}$ GABA were carried out in cultured hippocampal neurons (Figure 3A). Local YFP/CFP ratios and $\left[\mathrm{Cl}^{-}\right]_{\text {i }}$ measured by sCLM were highly correlated with $\left[\mathrm{Cl}^{-}\right]_{i}$ calculated by EGABA (Figure 3B and 3C). The correlation coefficient between the two measures was $0.65(n=38$ ROIs, 11 cells, $p<0.0001)$, consistent with the role of cytoplasmic microdomains in setting the local EGABA (Delpire and Staley, 2014; Glykys et al., 2017).

Utilizing another complimentary approach, we assayed subcellular $\left[\mathrm{Cl}^{-}\right]_{\mathrm{i}}$ using the pHinsensitive, $\mathrm{Cl}^{-}$sensitive, single-wavelength fluorophore MEQ (Biwersi and Verkman, 1991). We performed FLIM to avoid artifacts arising from subcellular variation in MEQ concentration. The FLIM measurements using MEQ delivered by the whole-cell recording pipette confirmed the variability of $\left[\mathrm{Cl}^{-}\right]_{\mathrm{i}}$ in dendrites of hippocampal pyramidal neurons in CA1 area (Figure 3D and 3E). The variance in $\left[\mathrm{Cl}^{-}\right]_{\mathrm{i}}$ measured by MEQ FLIM was also highly correlated with 
simultaneous electrophysiological measurements of EGABA measured in voltage clamp neurons by local application of GABA using direct visual guidance ( $\mathrm{n}=9$ ROIs, 7 cells; $\mathrm{p}=0.003$ ) (Figure 3F). These data support the idea that subcellular variance in $\left[\mathrm{Cl}^{-}\right]_{\mathrm{i}}$ is a significant contributor to the variance in $\mathrm{E}_{\mathrm{GABA}}$ (Table S1).

\section{Physiological chloride microdomains are stable and unaffected by pharmacological inhibition of cation-chloride cotransporters:}

Changes in $\left[\mathrm{Cl}^{-}\right]_{\mathrm{i}}$ are readily observed in response to alterations of the equilibrium conditions for CCCs using either osmotic or ionic perturbations of the perfusate (Thompson et al., 1988; DeFazio et al., 2000; Dzhala et al., 2010; Glykys et al., 2014b). This influence of transport equilibrium conditions on $\left[\mathrm{Cl}^{-}\right]_{\mathrm{i}}$ has led to the idea that $\mathrm{CCCs}$ set $\left[\mathrm{Cl}^{-}\right]_{\mathrm{i}}$ independently of the equilibrium conditions. To test the degree to which $\left[\mathrm{Cl}^{-}\right]_{i}$ microdomains are defined by CCCs, we imaged sCLM in stable extracellular ionic and osmotic conditions. We acquired time-lapse images for 50-60 minutes (Figure 4A). The ROIs (soma and dendrites of a single pyramidal neuron) were monitored and compared pixel by pixel with previous measurements every 10 minutes. Consistent with the prior noise analyses (Figure 2H), the microdomains remained highly stable in control conditions. Applying a high concentration of furosemide to block NKCC1 and KCC2 simultaneously (Gillen et al., 1996) did not alter the microdomain distributions (Figure 4A, 4C). Because the mobility of $\mathrm{Cl}^{-}$in neuronal cytoplasm is very high (Kuner and Augustine, 2000), $\left[\mathrm{Cl}^{-}\right]_{\mathrm{i}}$ should have rapidly homogenized after blockade of CCCs if $\mathrm{CCC}$ activity had created the $\left[\mathrm{Cl}^{-}\right]_{i}$ microdomains. The fact that this was not observed indicates that $\left[\mathrm{Cl}^{-}\right]_{\mathrm{i}}$ microdomains do not arise from local differences in cation- $\mathrm{Cl}^{-}$transport rates. While the correlation coefficient was stable over one hour, the value of the correlation coefficient was dependent on the expression levels of SCLM in different mice (Figure S5, panel D). This supports the idea that the spatial variance in SCLM signal is distinct from noise. To assess the lower bound of spatial stability that could be resolved with this technique, the same region of interest was acquired with the microscope shutter closed to quantify the much lower correlation of noise between the images (Figure $4 \mathrm{~B}$ and $4 \mathrm{C}$ ). As a positive control to demonstrate that changes in dendritic $\left[\mathrm{Cl}^{-}\right]_{\mathrm{i}}$ could be measured with these techniques, dendritic $\left[\mathrm{Cl}^{-}\right]$i was also measured in sCLM organotypic slices before and after seizure-like-events (SLE) (Glykys et al., 
2014b). Our data show that the dendritic $\left[\mathrm{Cl}^{-}\right]_{\mathrm{i}}$ in 4 different ROIs return to the same baseline value after SLE (Figure 4D and 4E), and that the return was independent of the initial (baseline) value. These results indicate that temporal fluctuations in $\left[\mathrm{Cl}^{-}\right]_{\mathrm{i}}$ can be resolved by this technique, and that $\left[\mathrm{Cl}^{-}\right]_{\mathrm{i}}$ microdomains persist after large transient $\mathrm{Cl}^{-}$fluxes.

\section{The stability of chloride microdomains is reduced by actin depolymerization:}

If the observed cytoplasmic $\left[\mathrm{Cl}^{-}\right]$i microdomains were created by the differential distribution of less mobile anionic macromolecules, then altering the distribution of those macromolecules should induce a corresponding change in chloride microdomains. To test this, we repeated the time-lapse two-photon imaging of sCLM organotypic slices (Figure 4) in the presence of latrunculin B which promotes net actin depolymerization (Morton, 2000) without affecting the morphology of dendrites (Kim and Lisman, 1999). To exclude secondary effects of cytoskeletal alterations on synapses and transporters, the experiments were performed in TTX, bumetanide (NKCC1 blocker) and VU 0240551 (KCC2 blocker). Following baseline imaging, neurons were continuously imaged for an additional hour after latrunculin B was added to the perfusate. Pixel by pixel correlation of dendritic and somatic ROIs from sequential images were compared with previous measurements (Figure 5A). The application of latrunculin B steadily changed the distribution of microdomains, evidenced by a reduction in the pixel-wise correlation coefficient of sequential images (Figure 5B). Over the same time period (40-60 minutes), the average percent change in pixel by pixel correlation in the presence of transporter blockers $(\mathrm{n}=12$ ROIs, mean $\pm \mathrm{SD}=-1.09 \% \pm 9.6 \%$ ) was significantly lower, i.e. microdomain stability was higher, than in the presence of transporter blockers and latrunculin B (Figure 5C, $n=13$ ROIs, mean \pm $\mathrm{SD}=-19.45 \% \pm 16.05 \% ; \mathrm{p}=0.002)$. The average pixel by pixel correlation was also compared between CFP images as control which did not significantly change during the same time period (mean transporter blockers $\pm \mathrm{SD}=-7.20 \% \pm 15.5 \%$; mean latrunculin $\mathrm{B} \pm \mathrm{SD}=-7.09 \% \pm 4.7 \%$, $\mathrm{p}=0.98$ ). The addition of latrunculin $\mathrm{B}$ to the perfusate containing transporter blockers did not alter the average percent change of $\left[\mathrm{Cl}^{-}\right]_{\mathrm{i}}$ observed after transport block (Figure 5D, mean transporter blockers $\pm \mathrm{SD}=14.14 \% \pm 24.2 \%$; mean latrunculin $\mathrm{B} \pm \mathrm{SD}=14.74 \% \pm 14.07 \%, \mathrm{p}=$ 0.94). This indicates that although CCCs are actively transporting $\mathrm{Cl}^{-}$across the membrane in this preparation, the CCCs do not define the distribution of microdomains. In contrast, 
latrunculin $\mathrm{B}$ modified the distribution of $\left[\mathrm{Cl}^{-}\right]_{\mathrm{i}}$ micodomains without additional change to the average $\left[\mathrm{Cl}^{-}\right]_{\mathrm{i}}$ by altering the macromolecular distribution through biopolymer disassembly.

\section{Discussion:}

These data obtained using multiple complimentary recording techniques support the existence of stable $\left[\mathrm{Cl}^{-}\right]_{i}$ microdomains and correspondingly unique responses to local $\mathrm{GABA} A$ receptor activation in the dendritic and somatic cytoplasm of CA1 pyramidal cells. The stability of microdomains over the entire time interval for which stability could be assessed, and the wide variance in the $\mathrm{E}_{\mathrm{GABA}}$ of pyramidal cells measured when individual presynaptic interneurons were stimulated, underscore the potential functional importance of $\left[\mathrm{Cl}^{-}\right]_{\mathrm{i}}$ microdomains for signaling at GABAergic synapses.

Neuronal $\mathrm{Cl}^{-}$microdomains have been a source of confusion and controversy. A wide variety of electrophysiological evidence supporting the nonuniform distribution of cytoplasmic $\mathrm{Cl}^{-}(\mathrm{Barna}$ et al., 2001; Duebel et al., 2006; Szabadics et al., 2006; Földy et al., 2010; Glykys et al., 2014b; Berglund et al., 2016; Untiet et al., 2016; Zorrilla de San Martin et al., 2017) has been challenged primarily by theoretical arguments (Luhmann et al., 2014; Doyon et al., 2016; Savtchenko et al., 2017; Düsterwald et al., 2018). The simplest argument for the existence of neuronal cytoplasmic $\mathrm{Cl}^{-}$microdomains is the fact that the vast majority of anions in the cytoplasm are relatively immobile. In neurons, the $\mathrm{GABA}_{A}$-permeant ions $\mathrm{Cl}^{-}$and $\mathrm{HCO}_{3}{ }^{-}$together make up only a minority of the intracellular anions. The rest of intracellular anions are amino acids and phosphates (Morawski et al., 2015), of which only a small minority are not associated with macromolecules (Masuda et al., 1990; Veech et al., 2002) such as nucleic acid species (Manning, 1978) and proteins (Gianazza and Righetti, 1980). These immobile anionic polymers are not uniformly distributed in the cytoplasm (Gut et al., 2018; Chen et al., 2020), so it is reasonable to expect that there is a nonuniform distribution of mobile anions to compensate for the distribution of immobile anions. Macroscopic nonuniform distributions of mobile ions are readily demonstrated experimentally using gels with fixed anionic charges (Procter, 1914; Fatin-Rouge et al., 2003; Golmohamadi et al., 2012), and these findings extend to anionic biopolymers that are not crosslinked into gels (Marinsky, 1985). Here we demonstrate that inhibition of 
polymerization of one such anionic macromolecule, actin, led to a proportionate change in the distribution of $\mathrm{Cl}^{-}$microdomains (Figure 5).

$\mathrm{Cl}^{-}$is not the only cytoplasmic ion whose spatial distribution would be affected by immobile anionic polymers. Due to electrostatic interactions, the concentration of cations is much higher in the hydration shells of these anionic polymers than in the free water that surrounds the shell (Gregor, 1951; Marinsky, 1993). This cytoplasmic inhomogeneity in cation concentration may provide insight into a long-standing problem: how can the high-velocity, membrane CCCs be at equilibrium over the wide range of observed steady-state values of $\left[\mathrm{Cl}^{-}\right]_{\mathrm{i}}$ (Table $\mathrm{S} 1$; Figure $\left.1 \mathrm{C}\right)$ ? The simple ionic stoichiometry of the transporters (Voipio and Kaila, 2000), coupled with their high transport velocity (Thompson et al., 1988; Staley and Proctor, 1999; Jin et al., 2005; Alfonsa et al., 2015a) and presumed homogenous cytoplasmic cation concentrations should lead to homogenous $\left[\mathrm{Cl}^{-}\right]_{\mathrm{i}}$, but this is not observed (e.g. Figure 2; 1C; Table S1). However, if the local cytoplasmic cation concentration also varies, then a much wider range of local steady-state $\left[\mathrm{Cl}^{-}\right]_{\mathrm{i}}$ could be in equilibrium with the CCCs: cytoplasmic $\mathrm{Cl}^{-}$microdomains (Figure 6).

The local variance of the concentrations (or more accurately, the activities) of local cations and anions provides a mean to reconcile the findings of transport biology (Voipio and Kaila, 2000; Doyon et al., 2016) with the impact of Donnan effects (Glykys et al., 2014b). That is to say, if transport is at equilibrium in each microdomain, then the highly regulated expression, phosphorylation and membrane trafficking of these transporters (Stein et al., 2004; Lee et al., 2010; Heubl et al., 2017; Garand et al., 2019) may serve to tailor transport to the characteristics of each microdomain, maintaining volume and average $\mathrm{Cl}^{-}$flux.

A related question is: if impermeant anions rather than transporters set $\mathrm{E}_{\mathrm{GABA}}$, why does inhibition of specific cotransporters cause small fractional changes in measured $\left[\mathrm{Cl}^{-}\right]_{i}(\mathrm{Figure}$ 5D) or EGABA (Hübner et al., 2001; Dzhala et al., 2005; Sipilä et al., 2009)? First, EGABA does not shift to resting membrane potential (Hübner et al., 2001; Brumback and Staley, 2008; Rinke et al., 2010), and $\left[\mathrm{Cl}^{-}\right]_{\mathrm{i}}$ does not shift to a passive distribution (Glykys et al., 2014b; Sato et al., 2017), as would be predicted if transporters set EGABA. Second, neuronal membrane permeability to $\mathrm{Cl}^{-}$is comprised of multiple $\mathrm{Cl}^{-}$cotransporters besides $\mathrm{KCC} 2$ and $\mathrm{NKCC} 1$, as well as $\mathrm{GABA}_{\mathrm{A}}$ and glycine receptors, whereas in the system described by Donnan, the membrane ionic permeabilities are independent of each other (Donnan, 1911). In neurons, for each membrane $\mathrm{Cl}^{-}$ 
cotransporter, the $\mathrm{Cl}^{-}$permeability is linked to transport of another molecular species with its own transmembrane free energy gradient. The sum of cotransport approximates an independent $\mathrm{Cl}^{-}$permeability (Glykys et al., 2014b; Glykys et al., 2017), but pharmacological block of any one cotransporter will shift the equilibrium $\left[\mathrm{Cl}^{-}\right]_{\mathrm{i}}$ accordingly. Fluorescence imaging of large numbers of neurons demonstrate that these shifts occur in both directions after inhibition of each transporter (Glykys et al., 2014b; Sato et al., 2017), as would be expected if neurons have unique transmembrane ionic gradients. Inhibition of both major CCCs at the same time led to very modest effects on $\left[\mathrm{Cl}^{-}\right]_{\mathrm{i}}$ microdomains (Figure $4 \mathrm{C}$ and $5 \mathrm{C}$ ), consistent with prior findings (Glykys et al., 2014b; Sato et al., 2017), whereas inhibition of actin polymerization significantly altered cytoplasmic $\mathrm{Cl}^{-}$microdomains (Figure 5B and 5C).

The heterogeneity of $\left[\mathrm{Cl}^{-}\right]_{\mathrm{i}}$ provides a potential explanation for the higher $\left[\mathrm{Cl}^{-}\right]_{\mathrm{i}}$ reported by fluorophores vs. the $\left[\mathrm{Cl}^{-}\right]_{\text {i }}$ recorded by electrophysiological measurements (e.g. Glykys et al., 2009; Dzhala et al., 2012; Sato et al., 2017; vs. Figure 1C). For example, a fluorophore sensing the $\mathrm{Cl}^{-}$in cytoplasmic free water but not the $\mathrm{Cl}^{-}$in hydration shells will return a value higher than the mean cytoplasmic $\mathrm{Cl}^{-}$. And if the fluorophore aligns with cationic regions of immobile proteins, it could report $\left[\mathrm{Cl}^{-}\right]_{\mathrm{i}}$ in those local hydration shells that are substantially higher than the mean cytoplasmic $\mathrm{Cl}^{-}$(Figure 6).

Other proposed explanations for the heterogenous $\left[\mathrm{Cl}^{-}\right]_{\mathrm{i}}$ include variation in the stoichiometry of $\mathrm{Cl}^{-}$cotransport (Brumback and Staley, 2008), obligatory water cotransport (Delpire and Staley, 2014; Glykys et al., 2019), and a low $\mathrm{V}_{\max }$ of transport relative to membrane $\mathrm{Cl}^{-}$flux (Doyon et al., 2016; Düsterwald et al., 2018). The last of these explanations appears to be a special case, because $E_{G A B A}$ at any synapse would be quite unstable within the physiological range of synaptic activity due to temporal fluctuations in synaptic $\mathrm{Cl}^{-}$influx vs saturable cotransport at $\mathrm{V}_{\text {max. }}$. Such temporal instability has only been observed at the maximal attainable levels of synaptic activity (Figure 4D, 4E; Huguenard and Alger, 1986; Staley et al., 1995; Köhling et al., 2000; Krishnan and Bazhenov, 2011; Alfonsa et al., 2015b; Silayeva et al., 2015; Buchin et al., 2016; Khazipov, 2016; Raimondo et al., 2017; Burman et al., 2019). The data presented here are most consistent with the idea that the equilibrium value of $\left[\mathrm{Cl}^{-}\right]_{\mathrm{i}}$ is defined by the local distribution of cytoplasmic anionic biopolymers. CCCs maintain that equilibrium value in the face of anionic membrane currents. This role for active $\mathrm{Cl}^{-}$cotransport becomes critical as the rate of synaptic 
activity increases (Staley and Proctor, 1999; Glykys et al., 2009; Glykys et al., 2014b; Doyon et al., 2016). The proposal that the observed $\mathrm{Cl}^{-}$distribution by displacement is only relevant at low rates of synaptic activity in vitro (Doyon et al., 2016; Düsterwald et al., 2018) is not consistent with in vivo measurements (Figure 2A, 2B). In vitro and in the presence of TTX, low rates of synaptic activity should dramatically reduce the discrepancy between measured $\mathrm{E}_{\mathrm{GABA}}$ and the equilibrium conditions for cation- $\mathrm{Cl}^{-}$cotransport if active transport were the primary mechanism of setting $\mathrm{E}_{\mathrm{GABA}}$, but this has not been observed (Figure 2; Table S1; Glykys et al., 2014b; Sato et al., 2017).

The range of variance of $\mathrm{E}_{\mathrm{GABA}}$ determined by activation of local interneurons agrees well with the ranges observed using perforated patch techniques (Figure 1). This raises the possibility of actively maintained motifs of immobile anions near the intra- and extracellular faces of the channels opened by $\mathrm{GABA}_{\mathrm{A}}$ receptors. The range of $\mathrm{E}_{\mathrm{GABA}}$ could be actively maintained by the local density and post-translational modifications of anionic intracellular structural species, such as gephyrin, actin, and tubulin (Sola et al., 2001), and extracellular sulfated glycosaminoglycans (Glykys et al., 2014a, b; Glykys et al., 2017).

The wide range in $\mathrm{E}_{\mathrm{GABA}}$ directly impacts the direction and magnitude of the response to GABA released from each interneuron, and potentially at each GABAergic synapse. This increases the range of possible interactions between GABAergic and excitatory inputs to include not only hyperpolarizing and shunting inhibition but also synapse-specific amplification (Gulledge and Stuart, 2003; Grienberger et al., 2017). The observed $25 \mathrm{mV}$ range in EGABA is continuously distributed. This distribution is not consistent with a result arising from inadvertent stimulation of two interneuron subtypes with distinct $\mathrm{E}_{\mathrm{GABA}}$ (Szabadics et al., 2006; Földy et al., 2010; Armstrong and Soltesz, 2012). Our findings do not invalidate those studies regarding $\mathrm{E}_{\mathrm{GABA}} \mathrm{vs}$ interneuron subtypes. Rather, interneuron subtype may be one of several important variables that determine $\mathrm{E}_{\mathrm{GABA}}$ at each pyramidal cell GABAA synapse.

$\mathrm{Cl}^{-}$microdomains were stable over an hour, which was the longest we could feasibly measure. Future studies to elucidate the cellular and synaptic specificity of the polarity of GABA signaling, the time range over which this polarity is stable, and its plasticity will clarify the role of neuronal cytoplasmic $\mathrm{Cl}^{-}$domains in neuronal signal processing and pathological states, such as medically intractable epilepsy (Cohen et al., 2002; Spruston et al., 2016). 


\section{Acknowledgments:}

KS was supported by NIH/NINDS 5R01NS40109-14. JG was supported by NIH/NINDS 1K08NS091248.

Author contributions: N.R. and K.J.S. designed research; N.R., K.P.N., J.G., and V.I.D. performed research; N.R., K.P.N., R.R. and T.J. analyzed data; N.R. and K.J.S. wrote the manuscript; K.P.N., J.G., K.P.L., V.I.D., K.T.K and R.R. participated in discussion and editing the manuscript.

Declaration of interest: The authors declare no competing interests. Dr. Jacob is currently an employee of Bayer Corporation.

\section{Figure legends:}

Figure 1: Inhomogeneity in responses to GABAergic interneurons. A) Puffing $50 \mu \mathrm{M}$ glutamate to the soma of visualized interneurons (labeled with tdTomato) around a single pyramidal cell evokes GABA currents with different reversal potentials. B) Range of EGABA measured in panel A. The colors of data points in panel B match the colors of traces and puff pipettes in panel A. The black dashed line shows the calculated $\mathrm{E}_{\mathrm{GABA}}$ based on the $\mathrm{Cl}^{-}$ concentration inside the recording pipette (pipette $\left.\mathrm{E}_{\mathrm{GABA}}\right)$. The puffing pipette was manually returned to the same area by the end of the experiment (puff 1 and puff 8 in panel A). The difference between the EGABA evoked by puff 1 and puff 8 was less than $2 \mathrm{mV}$ while the time interval between these two puffs was approximately 50 minutes. Although puff 8 was applied later than puff 1, its evoked EGABA was further away from the pipette EGABA compared to puff 1. These findings argue against the possibility that the $\left[\mathrm{Cl}^{-}\right]$inside the recording pipette homogenizes the dendritic $\left[\mathrm{Cl}^{-}\right]_{\mathrm{i}}$ C) Summary of our experiments $(\mathrm{n}=40$ cells $)$ and 20 separate studies indicating a wide rage in $\mathrm{E}_{\mathrm{GABA}}$ in age-matched $\mathrm{CA} 1$ pyramidal cells. 
Figure 2: Evidence for the existence of chloride microdomains from sCLM imaging. A) A representative in vivo two-photon imaging of a layer III neuron expressing sCLM from a P20 mouse and the color-coded image of YFP/CFP. The image shows a $20 \mu \mathrm{m}$ flatten z-stack. B) A histogram of somatic and dendritic YFP/CFP values restricted to a single $\mathrm{z}$ plane in the neuron shown in panel a. C, D). Two-photon imaging of an organotypic slice culture showing a hippocampal interneuron (C) and the dendritic variations in $\left[\mathrm{Cl}^{-}\right]_{\mathrm{i}}(\mathrm{D})$. E) A CA1 pyramidal cell from a hippocampal organotypic slice expressing sCLM. F) Top panel shows the rotated neuron in panel e with a red arrow. Bottom panel represents the magnified pseudo-colored $\left[\mathrm{Cl}^{-}\right]_{\mathrm{i}}$ maps of different segments of the dendrite. G) Histogram of all pixels derived from the dendrite of the neuron depicted in panel f. H) CLM expressing neurons were imaged for 30 minutes (180 frames at 6 frames per minute). The deviation from a white noise power spectrum is plotted against the number of timeframes averaged for the mean power spectra of both the neuronal YFP signal and closed-shutter noise. The resulting normalized curves converge toward significantly different values and demonstrate a decreased spatial variance over time in YFP signal vs normalized closed-shutter noise.

Figure 3: Simultaneous $\left[\mathrm{Cl}^{-}\right]_{i}$ imaging and electrophysiology. A) A representative hippocampal dissociated cultured neuron expressing sCLM and visualized by DualView using a CCD camera to simultaneously measure the YFP and CFP fluorescence. B) The $\left[\mathrm{Cl}^{-}\right]$i measured by fluorophore data (YFP/CFP) and the $\left[\mathrm{Cl}^{-}\right]_{\mathrm{i}}$ calculated from EGABA in dissociated cultured cells are highly correlated $(\mathrm{n}=38$ ROIs, 11 cells, $\mathrm{p}<0.0001)$. C) There is a significant correlation between the $\left[\mathrm{Cl}^{-}\right]_{\mathrm{i}}$ measurements by sCLM and $\left[\mathrm{Cl}^{-}\right]_{\text {i }}$ calculated by EGABA $(\mathrm{n}=38$ ROIs, 11 cells, $\mathrm{p}<0.0001)$. D) A representative example of a hippocampal pyramidal cell loaded with Alexa Fluor-594 and $\mathrm{Cl}^{-}$-sensitive, $\mathrm{pH}$-insensitive dye, MEQ. E) Fluorescence lifetime imaging of $\left[\mathrm{Cl}^{-}\right]_{\mathrm{i}}$ in hippocampal neurons confirms the variance of $\left[\mathrm{Cl}^{-}\right]_{\mathrm{i}}$ in dendrites. $\left[\mathrm{Cl}^{-}\right]_{\mathrm{i}}$ calculated from MEQ lifetime is visualized in pseudo color where the Alexa Fluor-594 ([ $\left.\mathrm{Cl}^{-}\right]_{\mathrm{i}}$-insensitive) signal sets the transparency value such that the $\left[\mathrm{Cl}^{-}\right]_{\mathrm{i}}$ value and corresponding color relate solely to the MEQ lifetime while the brightness of the pixel is set by Alexa Fluor-594 as a structural marker (gray colorbar, top right). No averaging or clustering was performed on MEQ images. Note the variety of $\left[\mathrm{Cl}^{-}\right]_{i}$ values and the frequent juxtaposition of relatively high and low values in close 
proximity. F) After loading the cells with MEQ, $50 \mu \mathrm{M}$ GABA was puffed to different visualized segments of dendrites and $\mathrm{E}_{\mathrm{GABA}}$ was measured. The $\left[\mathrm{Cl}^{-}\right]_{\mathrm{i}}$ measured by MEQ lifetime and $\left[\mathrm{Cl}^{-}\right]_{\mathrm{i}}$ measured by EGABA are significantly correlated $(\mathrm{n}=9$ ROIs, 7 cells, $\mathrm{p}=0.003)$.

Figure 4: Chloride microdomains are stable and are not defined by $\mathrm{Cl}^{-}$transport. A) Timelapse images of a hippocampal pyramidal cell, expressing sCLM in the presence of $1 \mu \mathrm{M}$ TTX before and after blocking KCC2 and NKCC1 with furosemide. B) The same region of interest was imaged while the microscope shutter was closed to measure the noise level and pixel by pixel correlation of the ROI as a control. C) The colocalization correlation analysis of the $\left[\mathrm{Cl}^{-}\right]_{\mathrm{i}}$ indicates that these dendritic $\mathrm{Cl}^{-}$microdomains remain stable before and after the application of $200 \mu \mathrm{M}$ furosemide. D) $\left[\mathrm{Cl}^{-}\right]_{i}$ of four dendritic ROIs were measured before and after a spontaneous seizure in a sCLM organotypic slice. $\left[\mathrm{Cl}^{-}\right]_{i}$ returns to the same baseline after the ictal period. E) Mean percent change in $\left[\mathrm{Cl}^{-}\right]_{\text {i }}$ measured in the 4 ROIs shown in panel D. Data are presented as mean $\pm \mathrm{SD}$.

Figure 5: Contribution of cytoplasmic anionic immobile polymers to $\mathrm{Cl}^{-}$microdomains. A) Time-lapse imaging of CA1 hippocampal sCLM expressing cells was performed in the presence of $1 \mu \mathrm{M}$ TTX, $10 \mu \mathrm{M}$ bumetanide and $1 \mu \mathrm{M}$ VU. Latrunculin B was added to the perfusate and a pixel by pixel correlation was performed before vs. after drug-induced actin depolymerization. B) The change in colocalization correlation of the ratiometric images demonstrates that the spatial stability of $\mathrm{Cl}^{-}$microdomains decreases after addition of $5 \mu \mathrm{M}$ latrunculin $\mathrm{B}$. C) The average pixelwise spatial correlation coefficient is significantly decreased after application of latrunculin B in addition to transport blockers compared to the time points when there are only transporter blockers in the bath. D) $\left[\mathrm{Cl}^{-}\right]_{i}$ averaged over the entire $\mathrm{ROI}$ is not changed by the addition of latrunculin $B$ to the perfusate. Data are presented as mean \pm SD.

Figure 6: An example of the effects of nonuniform distribution of immobile anionic charge on the distributions of mobile cationic and anionic charges. A) All ions in the illustrated regions of the protein hydration shell are in equilibrium with the ions in the cytoplasmic free water. The Donnan criteria (local charge balance, and equal free energies across equilibria) are fulfilled between each region and the free water, and between all elements of the free water. 
There is no net diffusion between regions of the hydration shell because of the effects of the fixed protein surface charge. Most cytoplasmic proteins bear a substantial net negative surface charge, so the majority of cytoplasmic $\mathrm{K}^{+}$resides in hydration shells, and the mean cytoplasmic $\mathrm{Cl}^{-}$is less than the $\mathrm{Cl}^{-}$in the free water. KCC2 is shown in equilibrium with the ions in the cytoplasmic free water. The additional osmotic pressure in hydration shells near high fixed surface charge density of the protein is a consequence of the locally higher concentration of counter-charged mobile ions and does not drive additional water movement (Helfferich, 1995), chapter 5). B) The concentrations shown in panel B are for illustration only; we do not yet know the actual ionic activities in the protein hydration shells or cytoplasmic free water. The example values for $\left[\mathrm{Cl}^{-}\right]_{\mathrm{i}}$ demonstrate that $\mathrm{E}_{\mathrm{GABA}}$ can vary from -1 to $-86 \mathrm{mV}$ while maintaining equilibrium with $\mathrm{KCC} 2$-mediated $\mathrm{KCl}$ membrane transport.

\section{Methods}

\section{Ethics statement}

All experiments were performed in accordance with protocols approved by the Center for comparative medicine (CCM) at Massachusetts General Hospital (MGH) and in accordance with the National Institute of Health Guide for the Care and Use of Laboratory Animals.

\section{Mice}

\section{Construction of the $S C L M$ targeting vector}

The STK1-HR gene-targeting vector was constructed from 129Sv mouse genomic DNA (GenOway, Lyon, France). The final targeting vector has the following features: (i) isogenic with $129 \mathrm{~Sv}$ ES cells, favoring the homologous recombination; (ii) asymmetrical homology arms (5' short arm- SA: $1 \mathrm{~kb}, 3$ ' long arm- LA: $4.3 \mathrm{~kb}$ ); (iii) transgenic cassette containing the sCLM-pA elements allowing the expression of the transgene under the control of the ubiquitous CAAG promoter sequences; (iv) LoxP flanked, combined STOP-neomycin selection (Neo) cassette allowing its excision through the action of Cre-recombinase, activating the sCLM overexpression; (v) presence of the Diphtheria Toxin A (DTA) negative selection marker reduces the isolation of non-homologous recombined ES cell clones (Figure S1A).

\section{Production of $s C L M$ targeted ES cell clones}


Linearized targeting vector was transfected into $129 \mathrm{~Sv}$ embryonic stem (ES) cells (GenOway, Lyon, France) according to GenOway's electroporation procedures. Polymerase chain reaction (PCR), Southern blot, and sequence analysis of G-418-resistant ES clones revealed the recombined locus in two clones. PCR across the $5^{\prime}$ end of the targeted locus used a forward primer hybridizing upstream of the 5' homology arm (5'-AAGACGAAAAGGGCAAGCATCTTCC $\left.-3^{\prime}\right)$ and a reverse primer hybridizing within the neomycin cassette (5'GCAGTGAGAAGAGTACCACCAAGAGTCC-3'). Two Southern blot assays were hybridized with an internal and an external probe to assess recombination accuracy at the respective 5' and 3' ends of the $s C L M$ locus. The absence of off-target mutations was confirmed by sequence analysis.

\section{Generation of chimeric mice and breeding scheme}

Recombined ES cell clones microinjected into C57BL/6 blastocysts gave rise to male chimeras with statistically significant ES cell contribution. These chimeras were bred with C57BL/6J mice expressing Cre recombinase to produce the $s C L M$ heterozygous line lacking the neomycin cassette. F1 genotyping was performed by PCR and Southern blot. PCR primers hybridizing upstream (5'-GGGCAACGTGCTGGTTATTGTGC-3') and downstream (5'ACAGCTCCTCGCCCTTGCTCAC-3') of the neomycin cassette allowed PCR identification of the 3195-base pair (bp) sCLM allele amplicon harboring the neomycin cassette, and the 177-bp amplicon lacking the neomycin cassette. Southern blot hybridization with an external probe allowed identification of the 3.7-kb $s C L M$ allele (Figure S1B, C).

Ratiometric $\left[\mathrm{Cl}^{-}\right]_{\mathrm{i}}$ measurements were performed on strain 129 sCLM mice (Grimley et al., 2013) by crossing sCLM-floxed mice with C57/BL6 Synapsin-Cre (for neuronal expression) or C57/BL6 DLX-Cre (for interneuron expression). FLIM experiments were performed on C57/BL6 wild type (WT) mice. Functional studies of $\left[\mathrm{Cl}^{-}\right]_{\mathrm{i}}$ microdomains were performed on DLX-Cre mice to visualize interneurons. Either sex was used for experiments.

\section{In vivo imaging}

Craniectomies were done under aseptic conditions, under anesthesia with inhaled isoflurane and in a stereotaxic frame. The temperature was regulated through a heating pad. The surgical site was sterilized with betadine and isopropyl alcohol, and a 2-3 mm incision was made in the scalp 
along the midline between the ears. A 5-7 mm diameter hole was drilled in the skull, $1 \mathrm{~mm}$ lateral, and posterior to Bregma (parietal region) using a high-speed micro-drill. Once the craniotomy is completed, a thin round cover glass ( 100 microns) is secured to the bone with a mixture of superglue and dental cement. Immediately after the craniectomy, the mice were imaged under the two-photon microscope while maintaining anesthesia and normo-temperature.

\section{Organotypic hippocampal slice preparation}

P6-P7 mice were used for preparation of organotypic slice cultures using the rocking plate technique (Romijn et al., 1988) or the membrane insert technique (Stoppini et al., 1991) for both electrophysiology and imaging. Isolated hippocampi were cut into $400 \mu \mathrm{m}$ slices on a McIlwain tissue chopper (Mickle Laboratory Engineering). Slices were then transferred to membrane inserts (PICMORG50; Millipore) or coverslips, which were placed in glass-bottomed six-well plates (P06-1.5H-N, CellVis). Both culture configurations were incubated at $5 \% \mathrm{CO} 2,36^{\circ} \mathrm{C}$ in Neurobasal-A growth medium supplemented with 2\% B27, $500 \mu \mathrm{M}$ GlutaMAX, and $0.03 \mathrm{mg} / \mathrm{ml}$ gentamycin (all from Invitrogen). Growth medium was changed every 3-4 day. Slices were used for experiments between DIV 6 and DIV 20.

\section{Dissociated cell culture preparation}

Hippocampal murine neurons were prepared based on the method of Beaudoin and colleagues (Beaudoin III et al., 2012), modified to use early post-natal mice and to employ a commercial kit (Worthington Biochemical, LK003150). P1-P4 mice are sacrificed by guillotine method cut just caudal to the ears. Bilateral incisions are made from ear to eye as far ventral as feasible, allowing rostral reflection of the calvaria. Using a spatula dipped in Gey's balanced salt solution (GBSS; Sigma, G9779) supplemented with glucose (Sigma) to $1.5 \%$ and then filter sterilized, brains from up to four animals are gently removed and to a $6 \mathrm{~cm}$ petri dish of glucose-supplemented GBSS in $6 \mathrm{~cm}$ petri dish on ice. Each hippocampus is dissected out and transferred to a second $6 \mathrm{~cm}$ petri dish of glucose-supplemented GBSS on a cold pack within the prep hood. Using a commercially available papain tissue dissociation kit (Worthington Biochemical, LK003150), hippocampi are transferred to Earle's Balanced Salt Solution (EBSS)-based papain solution supplemented with DNase in a $6 \mathrm{~cm}$ petri dish pre-equilibrated in $5 \% \mathrm{CO}_{2} 36^{\circ} \mathrm{C}$ incubator and chopped for 30 seconds with Bonn scissors before being returned to incubator for a 10- to 40-minute incubation 
commiserate with pup age. Halfway through incubation, tissue is triturated $\mathrm{x} 5$ with a $10 \mathrm{~mL}$ plastic pipette and returned to the incubator. Note that reduced yield from using plastic pipettes is deemed acceptable in order to avoid inconsistency of flame-polished glass tip diameter and subsequent trituration-related damage. Tissue is again triturated x 5 with a $10 \mathrm{ml}$ pipette and x3-4 with a $5 \mathrm{ml}$ pipette before being strained through a 40-micron basket filter (Corning, 431750) and transferred to a $50 \mathrm{ml}$ conical tube. Cell mixture is centrifuged 6 minutes at $300 \mathrm{x} \mathrm{g}$ and after carefully aspirating the supernatant the cell pellet is then resuspended with EBSS plus ovomucoid inhibitor albumin mixture supplemented with DNase (each part of Worthington kit). Gentle trituration with a $10 \mathrm{ml}$ pipette held several centimeters from the tube bottom is sufficient to resuspend. This mixture is then carefully and slowly overlaid atop $5 \mathrm{ml}$ of Ovoid protein in EBSS and centrifuged for 5 minutes at $70 \mathrm{x}$ g. The resulting pellet is resuspended in NeurobasalA media (Gibco, 10888-022) without supplementation and transferred to a fresh tube. Cell concentration and proportion surviving are calculated using trypan blue and a hemocytometer, and pre-plated to poly-D-lysine- and laminin-coated (Sigma, P0899 and laminin L2020, respectively) $19 \mathrm{~mm}$ coverslips (Electron Microscopy Services) or gridded glass-bottom $3.5 \mathrm{~cm}$ petri dishes (Ibidi, 81168) delivering 300 viable neurons per square millimeter at overall amounts between $2 \times 10^{5}$ and $5 \times 10^{5}$ cells in the absence of media supplementation. After a pre-plating period of two hours during which neurons will preferentially attach to the coated surface, unattached cells are aspirated, and fresh Neurobasal-A media supplemented as described above (Organotypic Hippocampal Slice Preparation). Fresh media replaces half of full volume every 2 to 3 days. Neurons were imaged between DIV 10 and DIV 20.

\section{Chloride measurements}

We used three methods to measure $\left[\mathrm{Cl}^{-}\right]_{\mathrm{i}}$ :

1. Two-photon sCLM imaging: The sCLM (Grimley et al., 2013) variant of CLM (Kuner and Augustine, 2000) was used for non-invasive $\left[\mathrm{Cl}^{-}\right]_{\mathrm{i}}$ imaging. sCLM consists of two fluorescent proteins CFP and YFP, joined by a short polypeptide linker which allows FRET-based imaging of $\left[\mathrm{Cl}^{-}\right]_{\mathrm{i}}$ (Grimley et al., 2013). For the $\mathrm{Cl}^{-}$imaging experiments that were performed without electrophysiological recordings, two-photon imaging was performed using a Fluoview 1000MPE with prechirp optics and a fast acousto-optical modulator (AOM) mounted on an Olympus BX61W1 upright microscope equipped with a $25 \times 1.05$ NA water-immersion objective 
(Olympus). A mode-locked Ti:Sapphire laser (MaiTai; Spectra-Physics, Fremont, CA) generated two-photon fluorescence with $860 \mathrm{~nm}$ excitation. Emitted light was detected through two filters in the range of 460-500 $\mathrm{nm}$ for cyan fluorescence protein (CFP) and 520-560 nm for yellow fluorescence protein (YFP). Two photomultiplier tubes (Hamamatsu Photonics) were used to simultaneously acquire CFP and YFP signals. Three dimensional stacks (3D) of raster scans in the $X Y$ plane $(0.33 \mu \mathrm{m} /$ pixel $X Y)$ were imaged at z-axis interval of $1 \mu \mathrm{m}$ for measuring the stability of microdomains (Figure 4 and 5) and a z-axis interval of $2 \mu \mathrm{m}$ for the rest of experiments. The pyramidal cell shown in Figure 1E was imaged with a higher resolution (0.099 $\mu \mathrm{m} /$ pixel $\mathrm{XY}$ and z-axis interval of $1 \mu \mathrm{m}$ ). Simultaneous two-photon and electrophysiological recordings were performed with a custom-built scanning microscope. Two-photon images were acquired using a custom-designed software (LabVIEW) and a scan head from Radiance 2000 MP (Bio-Rad), equipped with a 40×, 0.8 NA water-immersion objective (Olympus), and photomultiplier tubes with appropriate filters for CFP (450/80) and YFP (545/30). A SpectraPhysics Mai Tai laser was set to $860 \mathrm{~nm}$ for sCLM imaging. Serial images were collected with zaxis interval of $2 \mu \mathrm{m}$. The images were reconstructed offline either by ImageJ (PRID: SCR003070) or MATLAB (v2017a). To calculate $\left[\mathrm{Cl}^{-}\right]_{\mathrm{i}}$ using Image $\mathrm{J}$, a region of interest (ROI) was drawn around the cell body and dendrites and the ratio of YFP/CFP fluorescence intensity was measured. Images analyzed with MatLab were masked using image processing functions as described below. In either case the ratio was converted into $\left[\mathrm{Cl}^{-}\right]_{\mathrm{i}}$ by the following equation:

$$
\left[\mathrm{Cl}^{-}\right]_{\mathrm{i}}=\mathrm{K}_{\mathrm{d}} \frac{(\operatorname{Rmax}-R)}{(R-R \min )}
$$

Where $\mathrm{K}_{d}$ is the dissociation constant, $\mathrm{R}_{\max }$ is the ratio obtained in the absence of $\mathrm{Cl}^{-}$and $\mathrm{R}_{\min }$ is the ratio when sCLM is maximally quenched (Grimley et al., 2013) (Figure S3A).

2. Fluorescent Lifetime IMaging (FLIM) of MEQ: $1.5 \mathrm{mM}$ MEQ (6-methoxy-Nethylquinolinium iodide) was delivered to the cytoplasm via whole-cell recording pipette (Figure 2). Unlike sCLM, MEQ is insensitive to $\mathrm{pH}$ (Biwersi et al., 1992). The $\mathrm{Cl}^{-}$-sensitive signal of both fluorophores used in this study is independent of the concentration of dye due to either the ratiometric nature of SCLM, or the intrinsic nature of fluorescence lifetime as a concentrationindependent property. MEQ was excited at $750 \mathrm{~nm}$ using the custom-built scanning microscope detailed above with appropriate emission filter (390/65) and fluorescent lifetime was measured using Becker \& Hickl SPCImage software (Becker \& Hickl, Berlin, Germany). The selection of the ROI and calculation of MEQ lifetime was measured offline by a custom-written MATLAB 
(MathWorks Inc. Natick, MA) program. MEQ lifetime values were translated to $\left[\mathrm{Cl}^{-}\right]_{\mathrm{i}}$ using Stern-Volmer calibration (Figure S3B) (Biwersi et al., 1992). The detailed morphologies of the cells were visualized by adding $20 \mu \mathrm{M}$ Alexa Fluor-594 to the recording pipette. High-resolution Alexa Fluor-594 images $(0.307 \mu \mathrm{m} /$ pixel XY; $2 \mu \mathrm{m} /$ pixel Z) were used for precise selection of the ROI in MEQ lifetime images with XY resolution of $1.537 \mu \mathrm{m} /$ pixel and Z-axis interval of 2 $\mu \mathrm{m}$.

3. Electrophysiological measurement of $\mathrm{EGABA}_{\mathrm{GA}}$ A subset of experiments were performed using whole-cell and gramicidin perforated patch-clamp techniques (details in the electrophysiology section) in conjunction with SCLM imaging or FLIM. The reversal potential of GABAA-current $\left(\mathrm{E}_{\mathrm{GABA}}\right)$ was extracted from currents evoked by puff application of GABA to different segments of the dendrites while clamping the cell at various membrane potentials. GABA blocked by $2 \mu \mathrm{M}$ CGP55845. The size of the dendritic region of interest was determined by adding Alexa Fluor-594 inside the puffing pipette and measuring the region that the dye was diffused. $\left(\left[\mathrm{Cl}^{-}\right]_{\mathrm{i}}\right.$ was calculated using the Nernst equation:

$$
\mathrm{E}_{\mathrm{Cl}}=-\frac{R T}{F} \times \ln \frac{[\mathrm{Cl}] \mathrm{o}}{[\mathrm{Cl}] i}
$$

where $\mathrm{R}$ is the gas constant $\left(8.315 \mathrm{~J}_{\mathrm{mol}}^{-1} \cdot \mathrm{K}^{-1}\right), \mathrm{T}$ is the temperature in Kelvin, $\mathrm{F}$ is the Faraday's constant $\left(96.487 \mathrm{C} . \mathrm{mol}^{-1}\right),\left[\mathrm{Cl}^{-}\right]_{\mathrm{i}}$ is the intracellular concentration of chloride and $\left[\mathrm{Cl}^{-}\right]_{\mathrm{o}}$ is the extracellular concentration of chloride.

\section{Electrophysiology}

For electrophysiological recordings, organotypic slice cultures or dissociated cultured cells were transferred to a recording chamber and perfused with ACSF $(2.5 \mathrm{ml} / \mathrm{min})$ containing the following (in mM): $124 \mathrm{NaCl}, 1.25 \mathrm{NaH}_{2} \mathrm{PO}_{4}, 2.5 \mathrm{KCl}, 26 \mathrm{NaHCO}_{3}, 2 \mathrm{CaCl}_{2}$, and $2 \mathrm{MgSO}_{4}$ and 20 D-glucose, bubbled with $95 \% \quad \mathrm{O}_{2}$ and $5 \% \quad \mathrm{CO}_{2}$ at $34^{\circ} \mathrm{C}$. Two separate series of electrophysiological experiments were performed: 1. Gramicidin perforated patch-clamping on hippocampal dissociated cell cultures: cells were visualized using an upright microscope (Nikon Eclipse FN1) equipped with a 40×, 0.8 NA water-immersion objective (Nikon), a DualView image intensifier (Optical Insights, LLC) and a CCD camera (Chameleon3, Point Grey Research Inc.) for simultaneous acquisition of two separate images of CFP and YFP with X resolution of $1.996 \mu \mathrm{m} /$ pixel and Y resolution of $1.896 \mu \mathrm{m} /$ pixel (Figure 3A). Electrodes were pulled from borosilicate glass capillaries (Sutter Instruments) using a micropipette puller (model P-97, Sutter 
Instruments) with resistance 5-7 M $\Omega$ when filled with internal solution containing the following (in $\mathrm{mM}$ ): $140 \mathrm{KCl}, 5 \mathrm{MgCl}_{2}, 10 \mathrm{HEPES}, 5$ EGTA, osmolarity $290 \mathrm{mOsm}$, pH 7.25-7.35, adjusted with $\mathrm{KOH}$. Gramicidin-perforated patch clamping was performed as described previously (Rahmati et al., 2016). 2. Whole-cell patch-clamp recoding of hippocampal organotypic slices: These experiments were performed on wild type C57 rocking plate organotypic slices to simultaneously load the hippocampal pyramidal cells with MEQ for FLIM imaging and measure $\mathrm{E}_{\mathrm{GABA}}$ at different segments of the dendrites by $50 \mu \mathrm{M}$ GABA puff application (Figure 3E, F). Whole-cell patch-clamp recordings were also performed for functional evaluation of $\mathrm{Cl}^{-}$microdomains (Figure 1) on organotypic slices of DLX-Cre mice which were transfected on the day of slicing with tdTomato virus (Addgene-AAV9-CAG-FLEXtdTomato, $2 \mu \mathrm{l} / \mathrm{ml}$ culture media) to visualize interneurons. Patch pipettes with resistance 5-7 $\mathrm{M} \Omega$ were filled with an internal solution containing the following (in $\mathrm{mM}$ ): $124 \mathrm{~K}-\mathrm{MeSO}_{4}, 5$ $\mathrm{KCl}, 10 \mathrm{KOH}, 4 \mathrm{NaCl}, 10$ HEPES, 28.5 sucrose, 4 Na2ATP, $0.4 \mathrm{Na}_{3} \mathrm{GTP}, 1.4 \mathrm{mM}$ MEQ, osmolarity $295 \mathrm{mOsm}, \mathrm{pH}$ 7.25-7.35. For visualizing the whole morphology of the recorded cells, $20 \mu \mathrm{M}$ Alexa Fluor-594 hydrazide (Invitrogen) was added to the internal solution on the day of the experiment. Resting membrane potential (RMP) and input resistance were measured after whole-cell configuration was reached. Series resistance $\left(\mathrm{R}_{\mathrm{s}}\right.$; assessed in voltage-clamp mode by -5 or $-10 \mathrm{mV}$ voltage step) was monitored during the experiments to be stable. Only neurons with $R_{s}<20 \mathrm{M} \Omega$ were included in the analysis. For all the electrophysiological recordings, signal acquisition was performed using a Multiclamp amplifier (Multiclamp 700B, Molecular Devices) with Clampex 10 software (Molecular Devices). Signals were sampled at 10 $\mathrm{kHz}$ and filtered at $2 \mathrm{kHz}$. Data were stored on a PC for offline analysis after digitization using an A/D converter (Digidata 1440A, Molecular Devices).

\section{Image analysis}

To measure the stability of microdomains, colocalization analysis was performed by selecting a region of interest (ROI) and measuring YFP/CFP in each pixel of that ROI utilizing ImageJ (Figure S5A, B). Pixel intensity correlation analysis in time-lapsed images was performed by generating 2D intensity histograms and calculating a pixel-to-pixel Pearson's $r$ between sequential images, using the Coloc2 Fiji subroutine (Figure S5C). Pseudo-colored images of $\underline{\text { sCLM }}$ (Figure 2A, C, D) were generated by selecting the ROIs, measuring YFP/CFP in each 
pixel of that ROI and using the Pseudo-color Image Look-Up Tables (LUTs) Fiji subroutine. The remaining pseudo-colored images of $\underline{\mathrm{sCLM}}$ (Figure $2 \mathrm{~F}$ and $\mathrm{S} 4 \mathrm{E}$ ) were generated by reconstructing a flattened (2D) image using the $\mathrm{Cl}^{-}$insensitive CFP intensity to weight the contribution of each pixel's YFP/CFP ratio in a 3D image stack. Pseudo-color images of FLIM (Figure 3E and S4B) were generated by calibrating MEQ lifetime utilizing the Stern-Volmer relationship and calculating $\left[\mathrm{Cl}^{-}\right]_{\mathrm{i}}$ (Figure S4B) (Verkman et al., 1989). FLIM experiments included the brighter membrane impermeable dye Alexa Fluor-594 as well as MEQ in the recording pipette solution. The Alexa Fluor-594 ( $\mathrm{Cl}^{-}$-insensitive) signal was used to define the intracellular pixels. $\left[\mathrm{Cl}^{-}\right]_{i}$ was then calculated from the fluorescence lifetime of MEQ in those pixels. A $2 \mathrm{D}$ image was created from a 3D image stack by weighting the MEQ-derived $\left[\mathrm{Cl}^{-}\right]_{\mathrm{i}}$ values by the relative intensity of Alexa Fluor-594. The Alexa Fluor-594 signal intensity was used to determine the brightness of each pixel that was pseudo-colored based on the calculated $\left[\mathrm{Cl}^{-}\right]_{\mathrm{i}}$. In pixels where MEQ signal is indistinguishable from background noise, no pseudo-color is assigned, and the pixel is colored using a grey-scale Alexa Fluor-594 signal. The greyscale then demonstrates the dendritic structure in areas where MEQ signal is inadequate. For noise analysis, a representative 30-minute time series (180 frames) of acutely sliced CLM-expressing CA1 pyramidal cells imaged in the presence of TTX is compared to the noise acquired from a similar series acquired with the shutter closed (Figure 2H). MATLAB is used to perform a linescan to represent each neuron as a vector of intensity values and to compute subsequent Fast Fourier Transforms (FFTs) of CLM YFP intensity and the corresponding channel closed-shutter noise intensity (see detailed noise analysis below). As the power spectrum of more timeframe images are averaged, the power of noise from a closed shutter will converge to that of white noise. Power obtained from variations due to persistent structural differences such as microdomains will not converge to a white noise power spectrum, converging instead to a greater power difference from white noise than shutter noise (Figure $2 \mathrm{H}$ ).

\section{Detailed noise analysis:}

To test whether the observed spatial variance in $\left[\mathrm{Cl}^{-}\right]_{\mathrm{i}}$ could arise from noise, we compared the averaged power spectra of the spatial frequencies of $\left[\mathrm{Cl}^{-}\right]_{\mathrm{i}}$ reporter CLM intensity values in the neurons to the power spectrum of closed-shutter noise. Noise analysis was performed with 
customized scripts in MATLAB utilizing Fourier transform and image analysis functions therein.

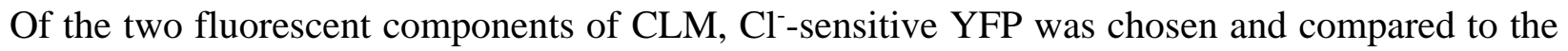
noise detected with the laser shutter closed over the same number of timeframes for each neuron. Dendrites or soma were chosen based on persistent signal strength and linearized by line scan. The YFP signal of each frame was co-registered to the first frame and applied to both the YFP and closed-shutter noise image of that frame. Spatial Fast Fourier Transforms (FFTs) were computed on these intensity signals to obtain the power (amplitude squared) of the observed YFP and closed-shutter noise values at a spectrum of wavelengths from $0.794 \mu \mathrm{m}$ (exclusive) to 25.4 $\mu \mathrm{m}$ (inclusive), bound by the Nyquist wavelength and the distance equivalent to the largest exponent of base 2 that did not exceed the length of the smallest vector in pixels, respectively. The closed shutter noise power spectra are rescaled by the ratio of area under the curves between the mean power spectrum of the neuronal signal and shutter noise. The white noise power spectrum was generated from averaging the power spectra of 72,000 vectors created from 400 random shuffles of each of 180 timeframes. Defining $X_{1 \ldots 180}$ as the vectors at 180 different timeframes of observed intensity values for noise from a closed shutter or a signal from a neuron, we obtain 400 randomly shuffled versions for each 180 timeframe vectors $X_{1 \ldots 180}$ assigned to $A_{1 \ldots 72,000}$. By computing the Fast Fourier Transform (FFT) on each of the vectors $A_{1 \ldots 72,000}$ and averaging the square of each result, we obtain the respective white noise power spectrum $W$ for either a neuronal signal or closed shutter noise defined as:

$$
W=\operatorname{mean}\left(F F T\left(A_{1}\right)^{2}, \operatorname{FFT}\left(A_{2}\right)^{2} \ldots F F T\left(A_{72,000}\right)^{2}\right)
$$

The absolute area between the cumulative average of either the power spectra of the YFP neuronal signal or the closed-shutter noise and their respective white noise power spectrum is calculated at each timeframe. The resulting curves are normalized and plotted as a function of frame number such that the number of frames included in the average power spectrum is equal to the frame number. Comparing the behavior of the averaged power spectra of signal intensity versus closed-shutter noise as a function of the number of frames averaged allows a direct comparison of heterogeneity. Heterogeneity that is random and transient (i.e. noise) will average out with increasing number of frames, but heterogeneity that is persistent will not. 


\section{Quantification and statistical analysis}

Imaging data were analyzed with ImageJ (http://imagej.nih.gov/iillj/) or MATLAB. Details of the analysis are included in "image analysis" section of STAR Methods. Statistical analysis of the data was done in GraphPad Prism (GraphPad Prism 8). Statistics were assessed with twotailed unpaired Student's t tests when comparing two groups. The number of data points (n) and the statistical significance ( $p$ value) are stated in figure legends. 
bioRxiv preprint doi: https://doi.org/10.1101/2020.06.29.178160; this version posted June 29, 2020. The copyright holder for this preprint (which was not certified by peer review) is the author/funder. All rights reserved. No reuse allowed without permission.

\section{Figures:}

\section{Figure 1.}

A $50 \mu \mathrm{M}$ glutamate puff

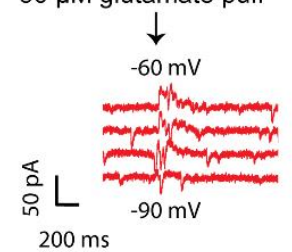

$200 \mathrm{~ms}$
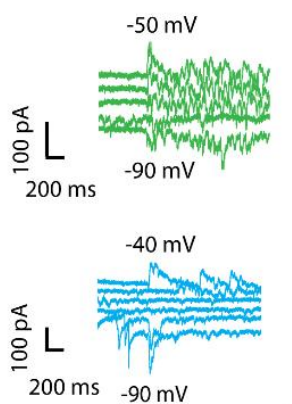

$200 \mathrm{~ms}-90 \mathrm{mV}$
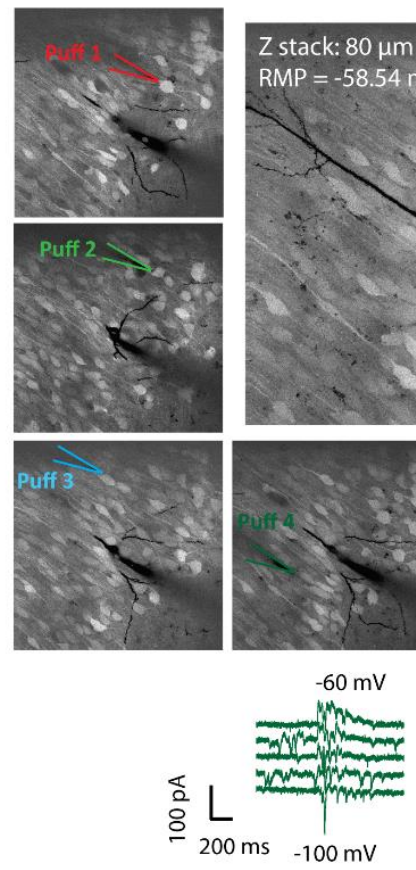
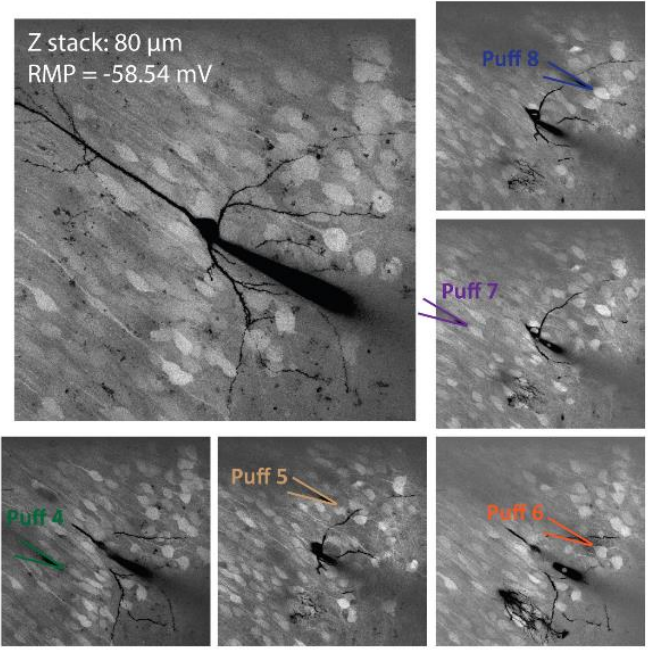

$-40 \mathrm{mV}$

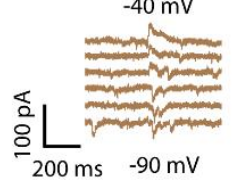

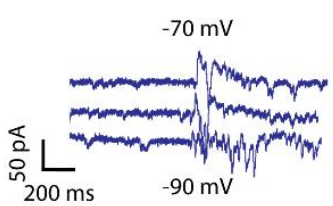
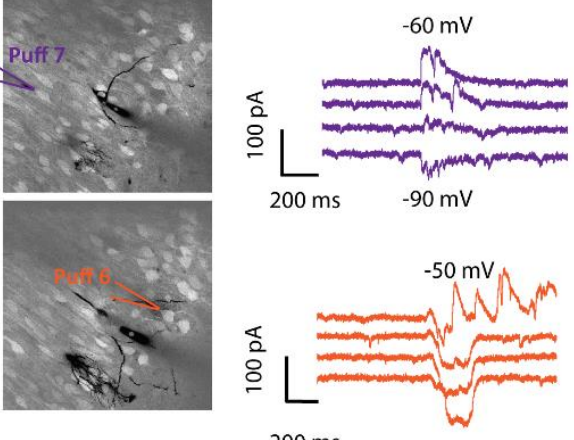

$200 \mathrm{~ms}$

$-80 \mathrm{mV}$

B

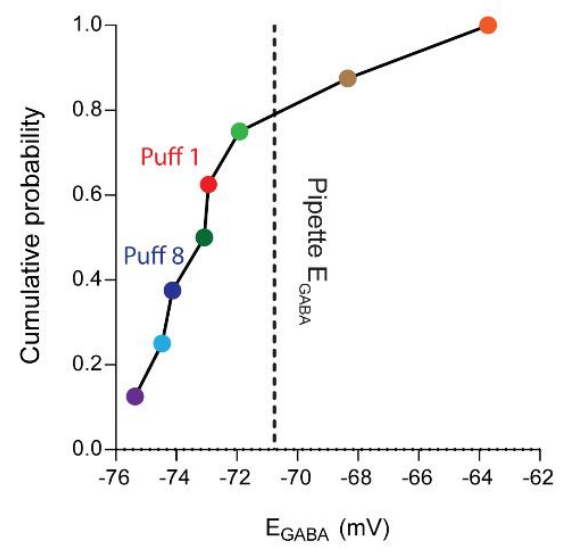

C

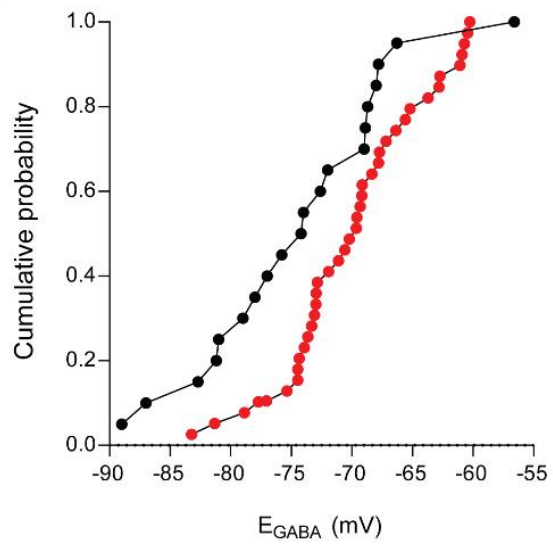

- Interneuron stimulations $n=40$ cells

- Other studies (20 independent group means) 


\section{Figure 2.}

A

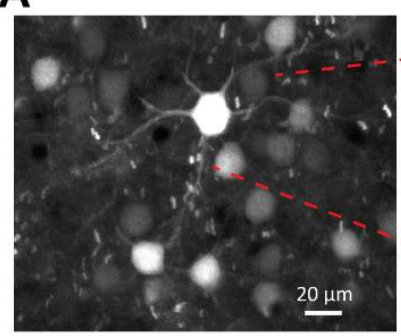

C Interneuron

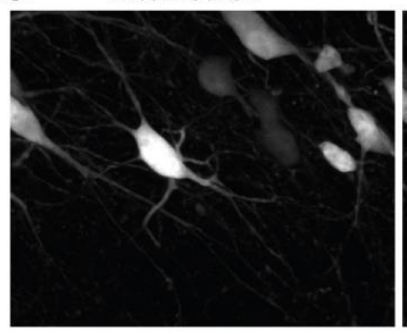

E Pyramidal cell
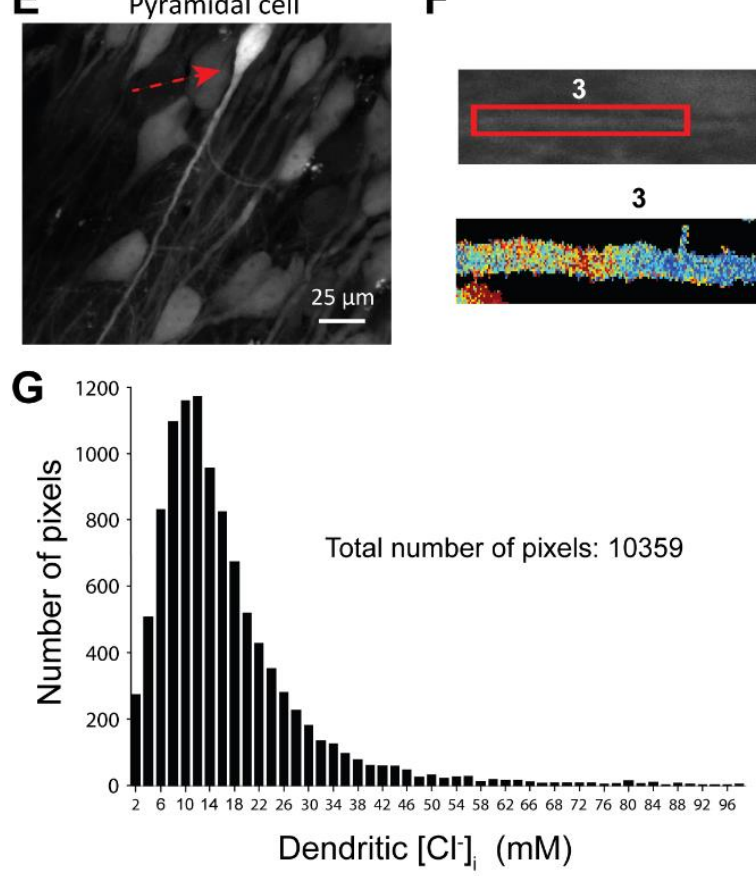

F
B

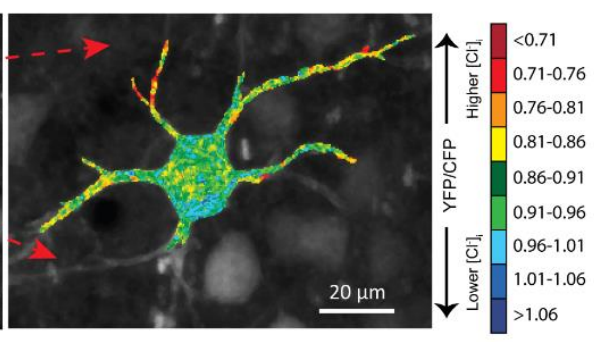

D
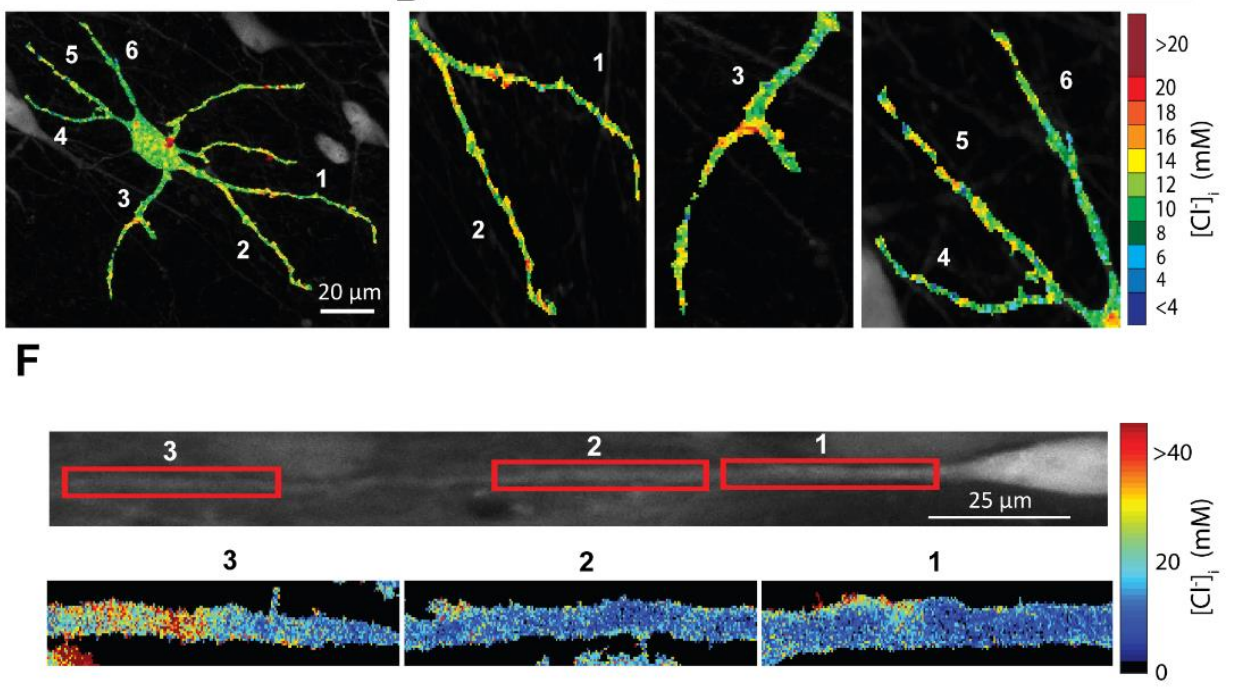

H

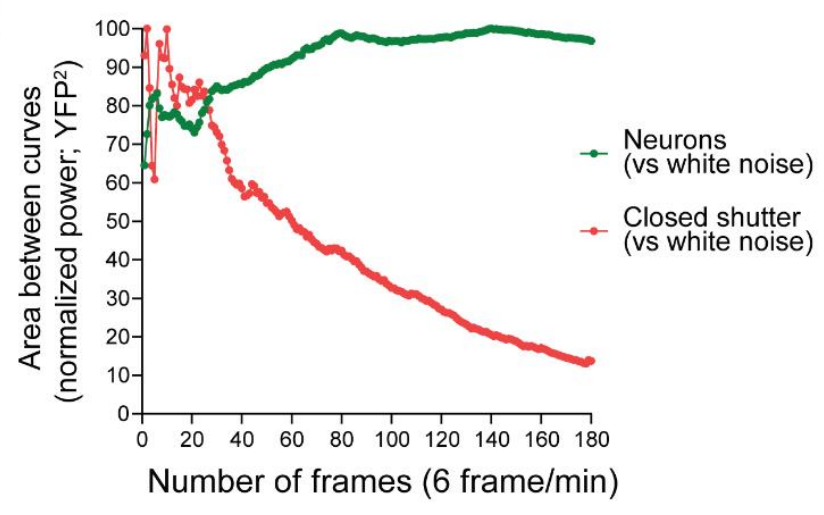


bioRxiv preprint doi: https://doi.org/10.1101/2020.06.29.178160; this version posted June 29, 2020. The copyright holder for this preprint (which was not certified by peer review) is the author/funder. All rights reserved. No reuse allowed without permission.

\section{Figure 3.}

A

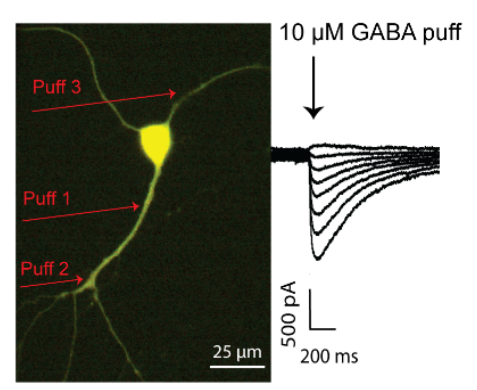

D

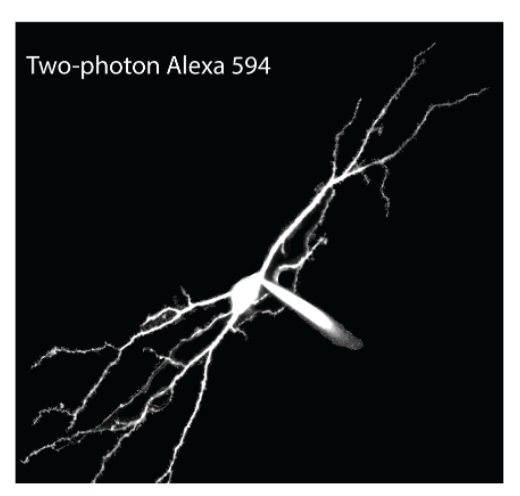

B

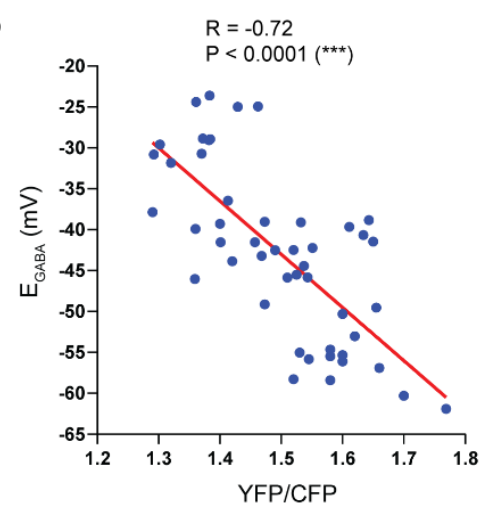

E

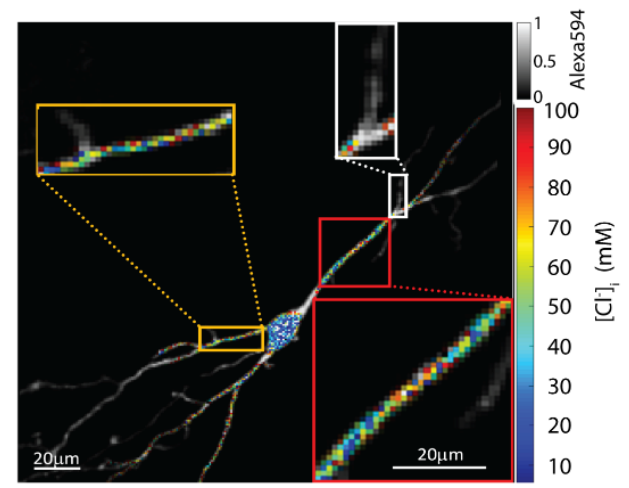

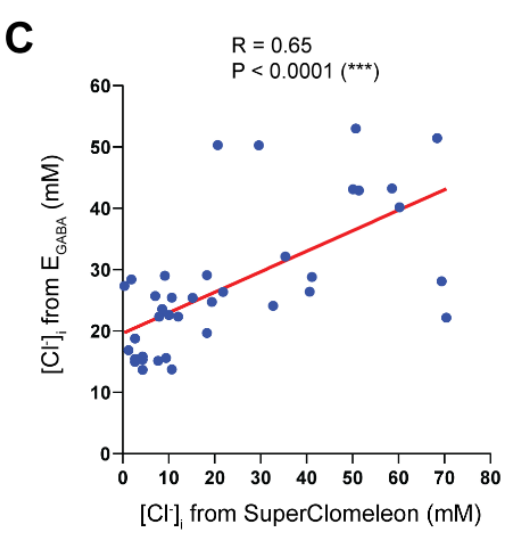

F

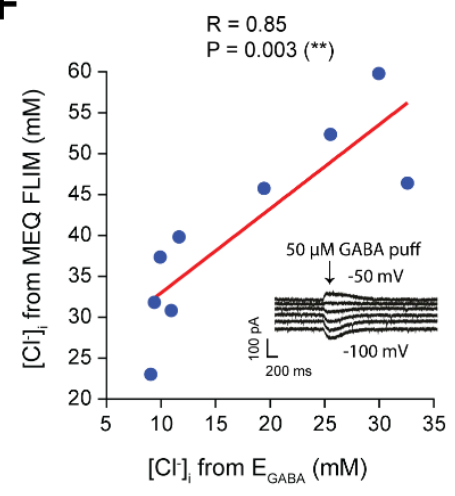


bioRxiv preprint doi: https://doi.org/10.1101/2020.06.29.178160; this version posted June 29, 2020. The copyright holder for this preprint (which was not certified by peer review) is the author/funder. All rights reserved. No reuse allowed without permission.

\section{Figure 4.}

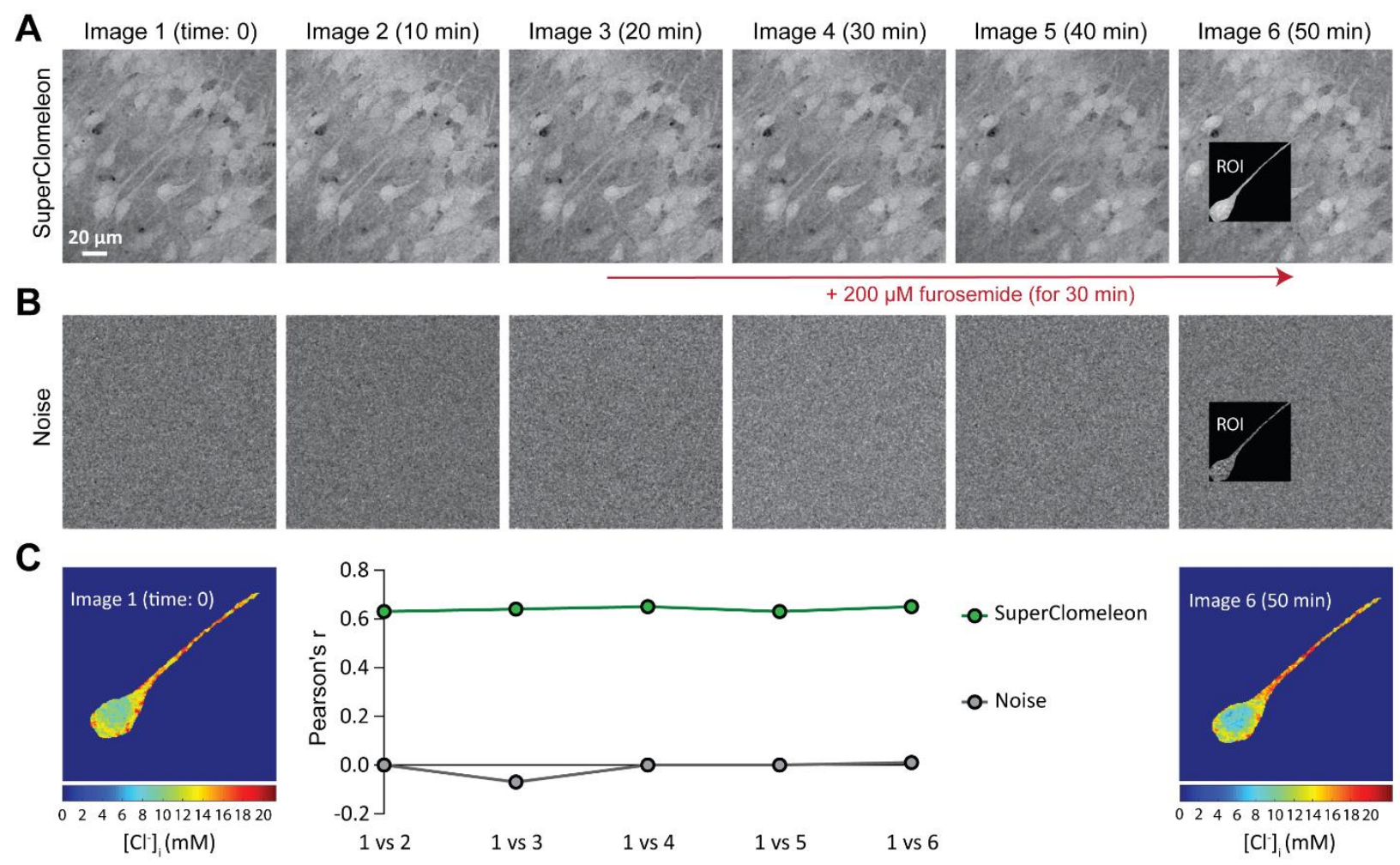

D

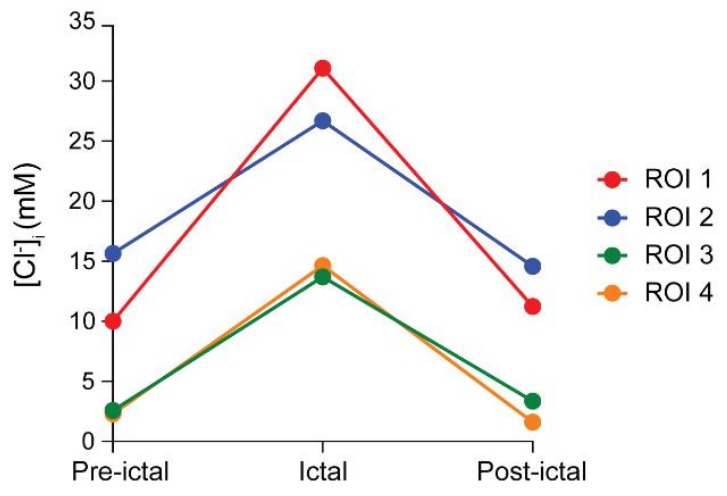

E

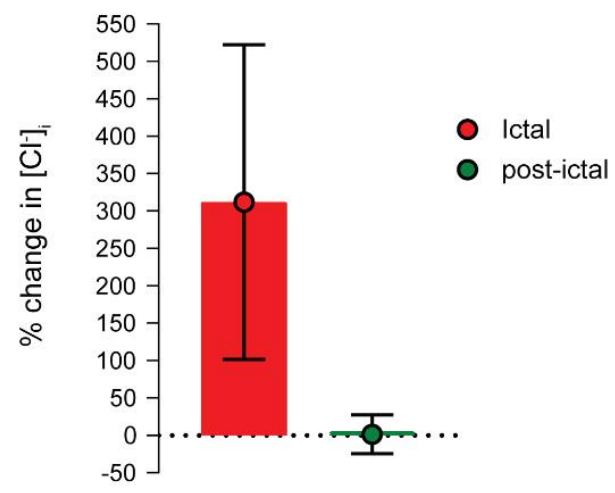




\section{Figure 5.}

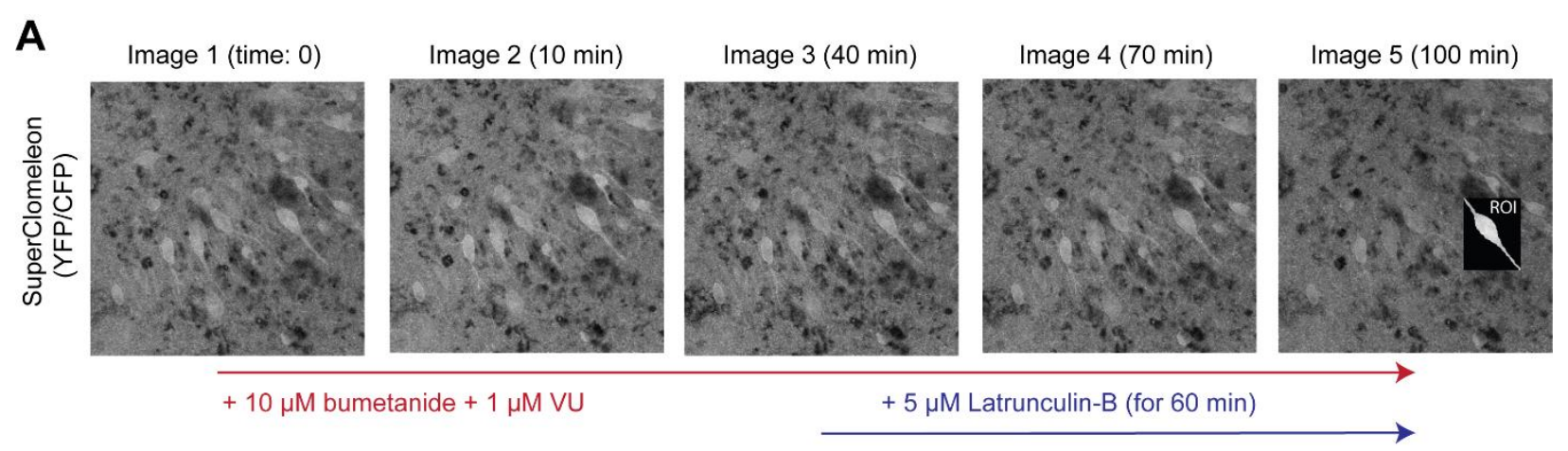

B

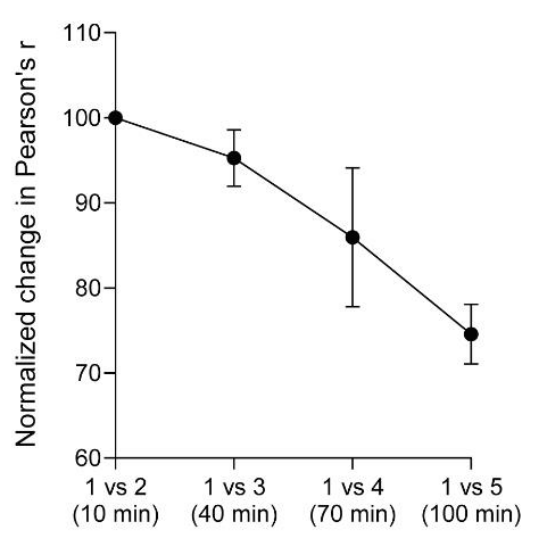

Time lapse images

C

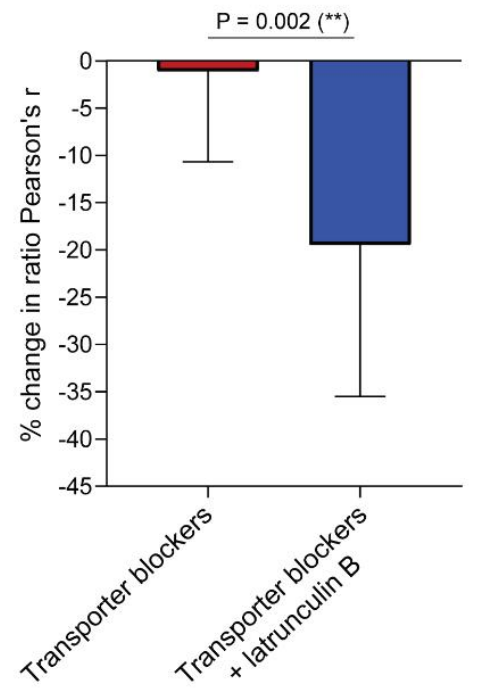

D

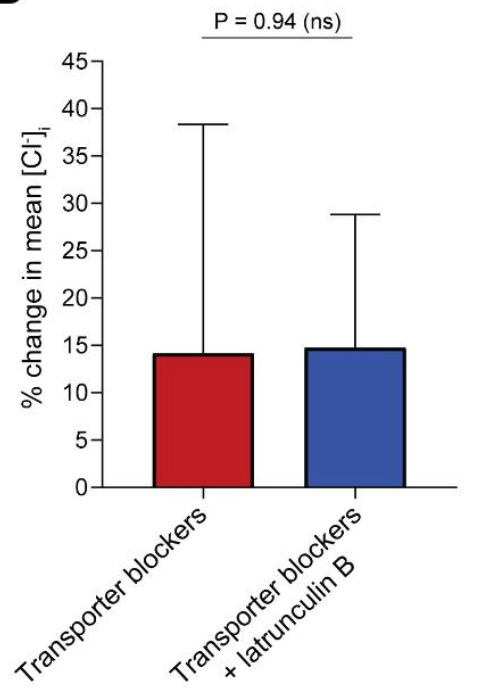




\section{Figure 6.}

A
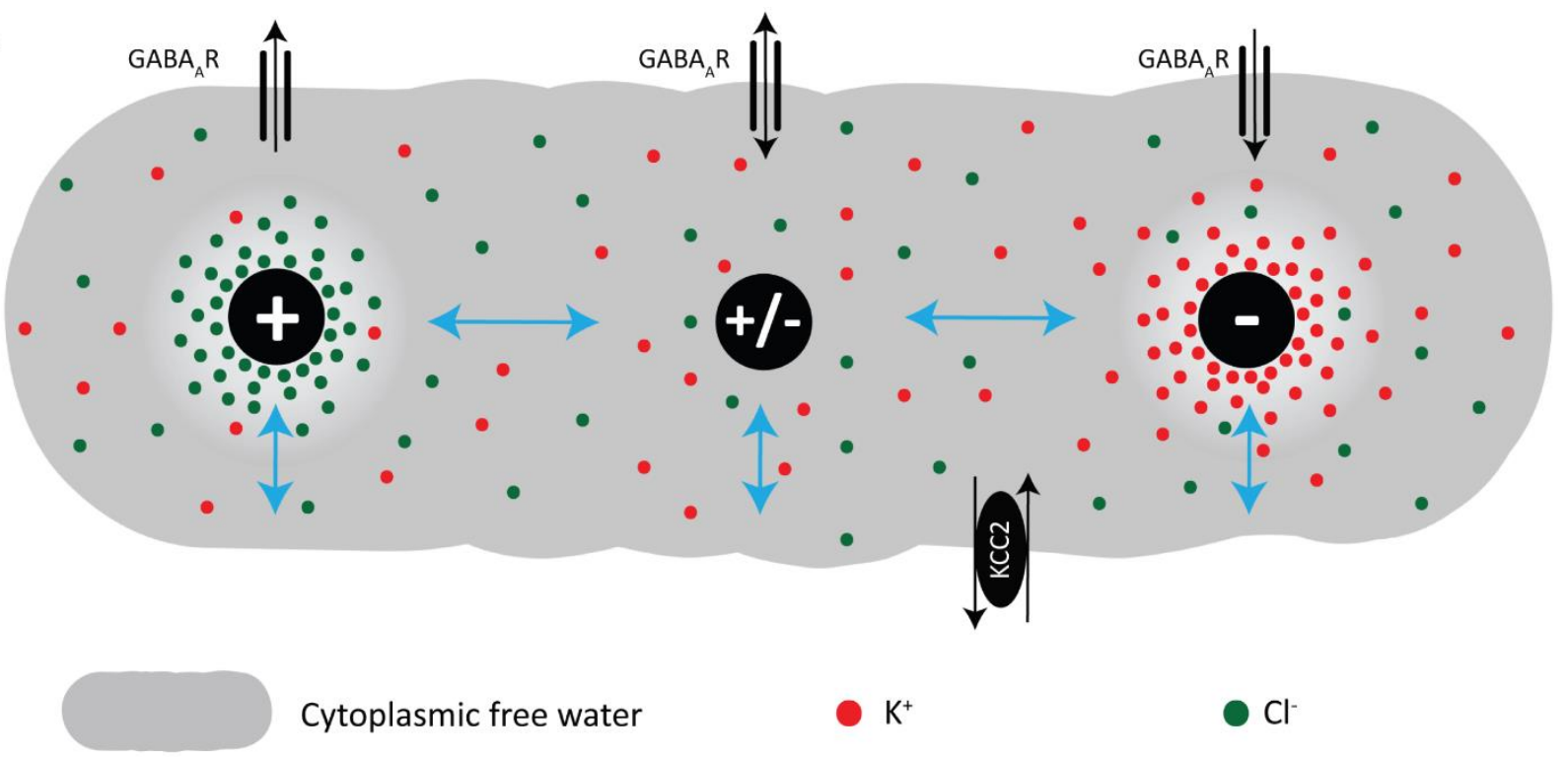

- $\mathrm{K}^{+}$

$\mathrm{Cl}^{-}$

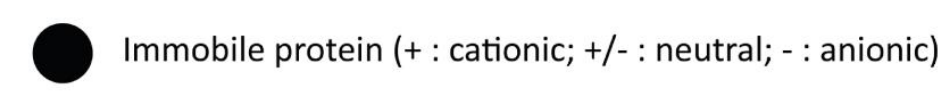

$\longleftrightarrow$ Equilibrium

B

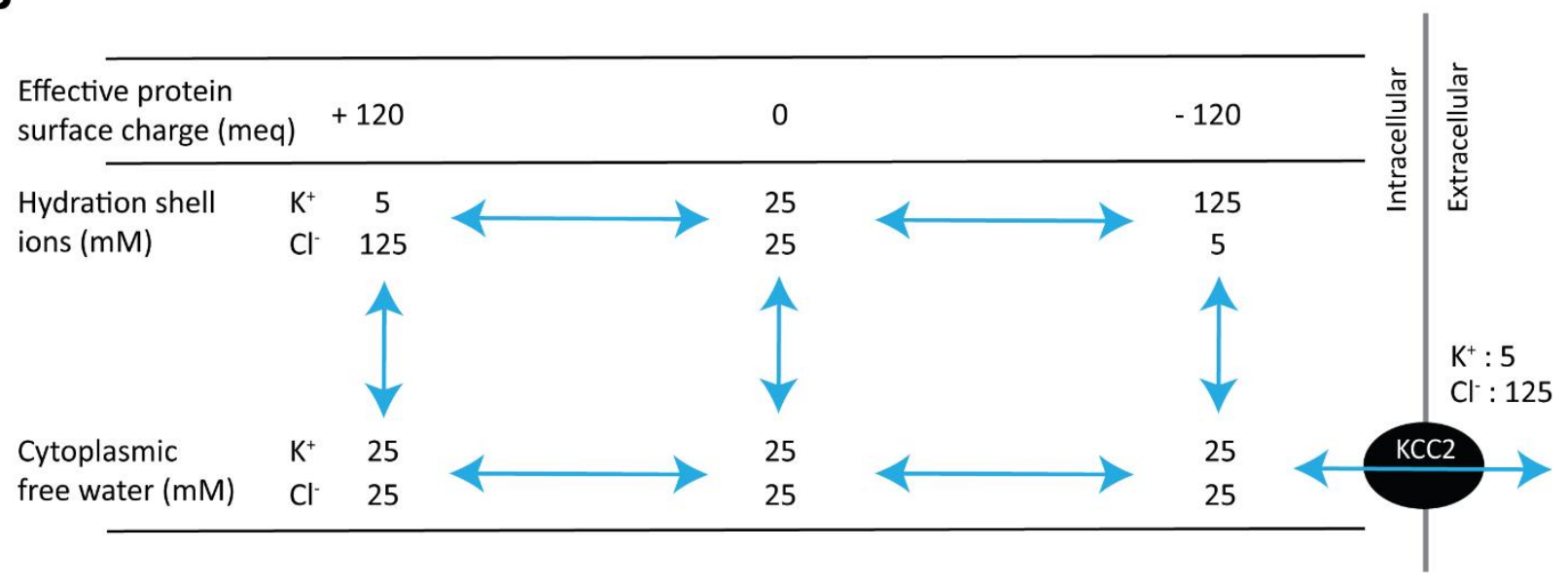




\section{Supplemental Information}

\section{Table S1}

\begin{tabular}{|c|c|c|c|c|}
\hline \multicolumn{1}{|c|}{$\mathbf{E}_{\text {GABA }}(\mathbf{m V})$} & Technique & Citation & Notes \\
\hline 1 & -89.0 & Gramicidin & Nakahata, Miyamoto et al. 2010 & \\
\hline 2 & -87.0 & Gramicidin & Ormond and Woodin 2009 & \\
\hline 3 & -82.7 & Gramicidin & Ilie, Raimondo et al. 2012 & \\
\hline 4 & -81.2 & Gramicidin & Galanopoulou 2008 & Female mice \\
\hline 5 & -81.0 & Cell-attached & Chorin, Vinograd et al. 2011 & \\
\hline 6 & -79.0 & Gramicidin & Pavlov, Scimemi et al. 2011 & \\
\hline 7 & -78 & Gramicidin & Zhan, Nadler et al. 2006 & \\
\hline 8 & -77.0 & Gramicidin & Lagostena, Rosato-Siri et al. 2010 & \\
\hline 9 & -75.8 & Gramicidin & Tanaka, Saito et al. 1997 & Evoked in SLM \\
\hline 10 & -74.2 & Gramicidin & Galanopoulou 2008 & Male mice \\
\hline 11 & -74 & Gramicidin & Tyzio, Holmes et al. 2007 & \\
\hline 12 & -72.6 & Gramicidin & Tanaka, Saito et al. 1997 & Evoked in SP \\
\hline 13 & -72.0 & Cell-attached & Tyzio, Minlebaev et al. 2008 & \\
\hline 14 & -69.0 & Gramicidin & Riekki, Pavlov et al. 2008 & \\
\hline 15 & -68.9 & Gramicidin & Barmashenko, Hefft et al. 2011 & \\
\hline 16 & -68.7 & Gramicidin & Raimondo, Kay et al. 2012 & \\
\hline 17 & -68.0 & Gramicidin & MacKenzie and Maguire 2015 & \\
\hline 18 & -67.8 & Gramicidin & Sauer, Strüber et al. 2012 & \\
\hline 19 & -66.3 & Gramicidin & Balena, Acton et al. 2010 & \\
\hline 20 & -56.6 & Gramicidin & Yang, Rajput et al. 2015 & \\
\hline
\end{tabular}

Supplemental Table 1: Reported range of $\mathbf{E}_{\mathrm{GABA}}$ in separated studies. 20 group means of $\mathrm{E}_{\mathrm{GABA}}$ measurements using gramicidin and cell-attached techniques in age-matched CA1 pyramidal cells. SP: Stratum pyramidale, SLM: stratum lacunosum-moleculare. 


\section{Figure S1}

\section{A}

Targetting vector (STK1-HR)

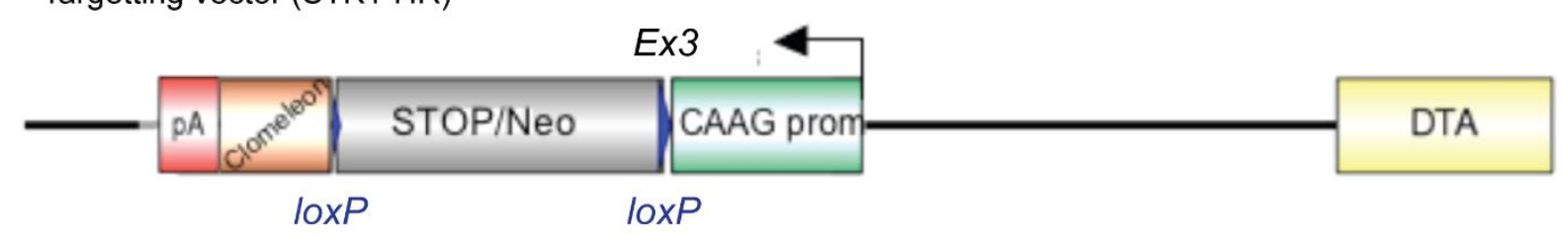

B

\begin{tabular}{|c|c|c|}
\hline primer name & primer sequence 5'-3, & $\begin{array}{c}\text { expected } \\
\text { PCR size }\end{array}$ \\
\hline $0033-$ KIN-ROSA-GX6043 & AAGACGAAAAGGGCAAGCATCTTCC & \multirow{2}{*}{$3680 \mathrm{bp}$} \\
\hline 0061 -HAT-STOP-27461 & CATGGTAAGTAAGCTTGGGCTGCAGG & \\
\hline
\end{tabular}

C
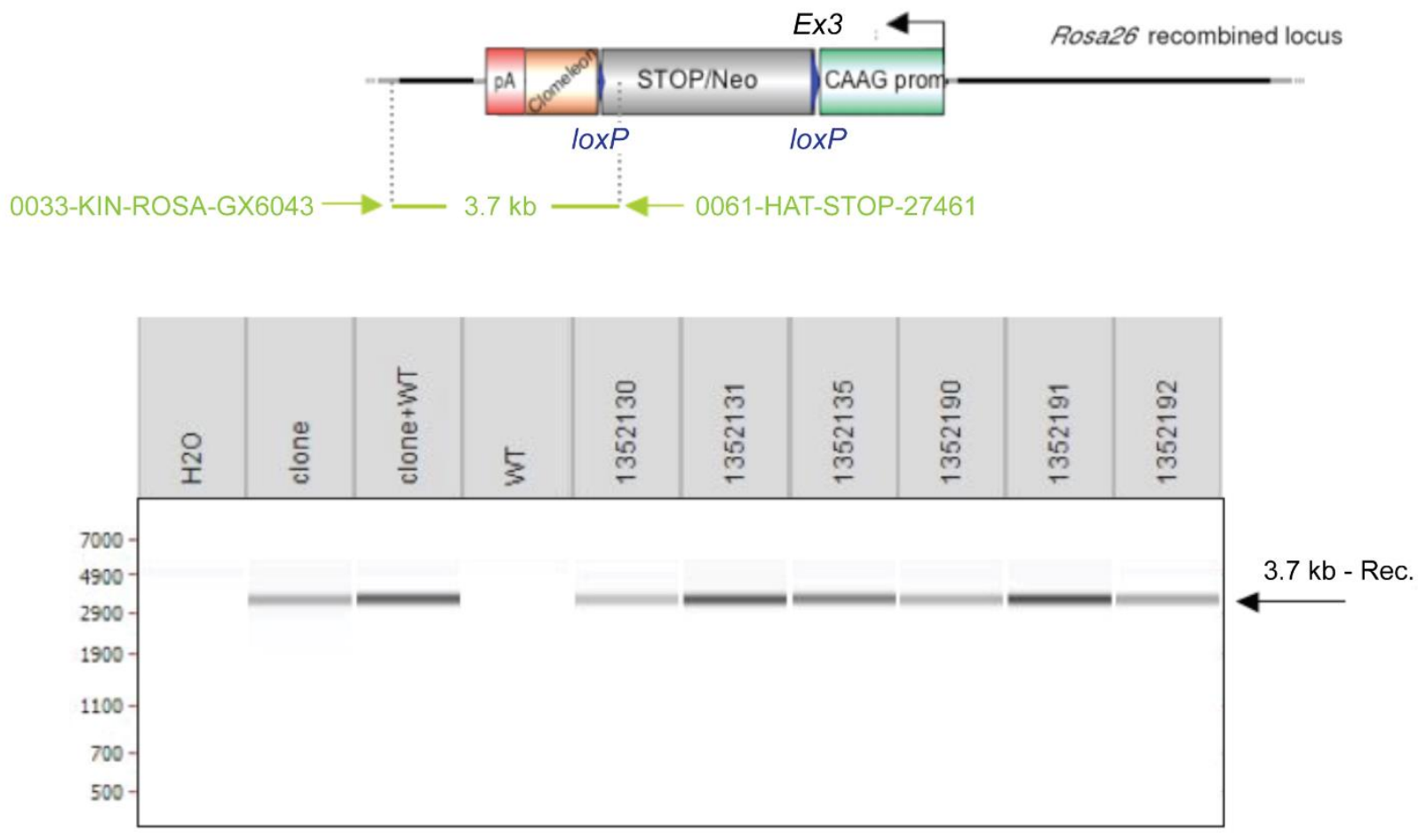
Supplemental Figure 1: Construction of the $s C L M$ targeting vector and Generation of chimeric mice. A) Schematic representation of Rosa26 Knock-in targeting vector. Diagram is not depicted to scale. LoxP sites are represented by blue triangles. The SCLM transgene is depicted as a brown box and the polyA as a red box. The combined STOP-neomycin selection cassette is indicated as a grey box. The ubiquitous CAAG promoter is represented by a green box. The DTA negative selection cassette is represented by a yellow box. B) primer set for the detection of the non-excised recombined conditional Knock-in allele. c. The genotype of the pups derived from the F1 breeding with Cre deleter mice were tested by PCR enabling the detection of the neomycin cassette. PCR using recombined ES cell clones as template, alone or in the presence of $10 \mathrm{ng}$ C57BL/6 genomic DNA (clone; clone+WT) served as positive controls. PCR with wild-type C57BL/6 genomic DNA (WT) and without DNA (H2O) as template served as negative controls. PCR picture was obtained after loading of PCR reactions on LabChip ${ }^{\circledR}$ system from Caliper LifeSciences.

\section{Figure S2}

A

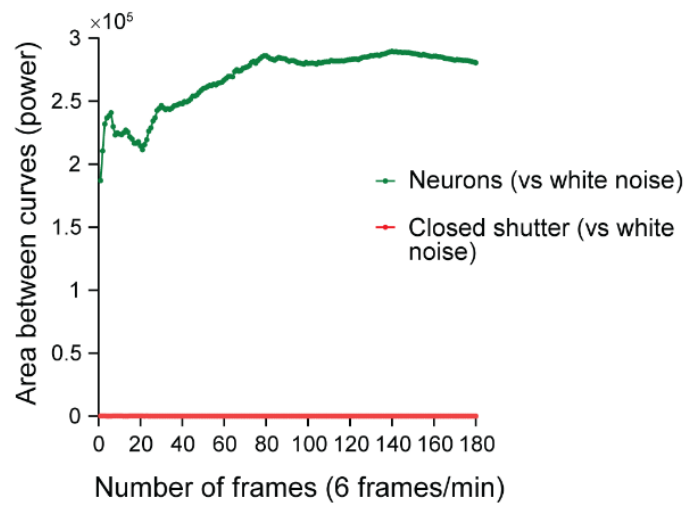

B

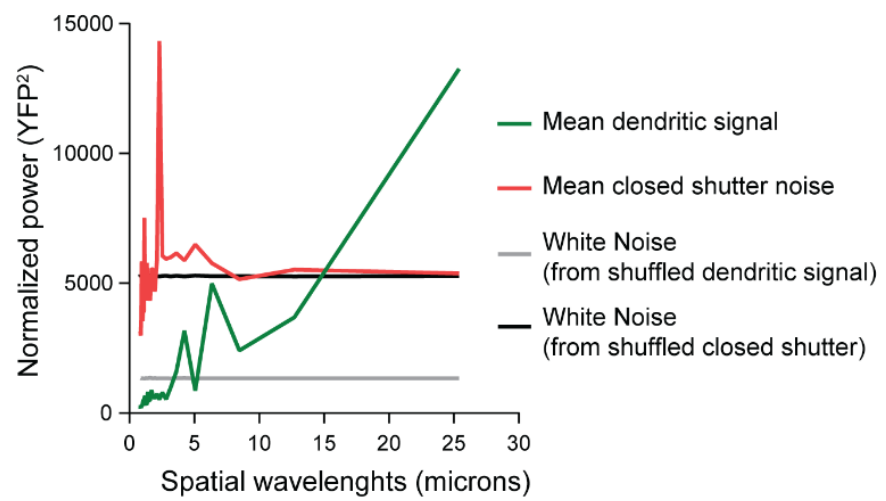

Supplemental Figure 2: Signal vs noise analysis. A) From 180 Clomeleon timeframes, the absolute area between the mean power spectra and that of white noise for both the neuronal YFP fluorescence signal and closed shutter noise is plotted against the number of timeframes included in the mean (green and red, respectively). These are the raw curves which are then normalized in panel B. B) The mean power spectrum of closed shutter noise is normalized by a ratio to have total power equivalent to that of the mean power spectrum of the YFP dendritic signal (red and green, respectively). A white noise power spectrum is generated for either normalized shutter noise or dendritic signal (black and gray, respectively). 


\section{Figure S3}
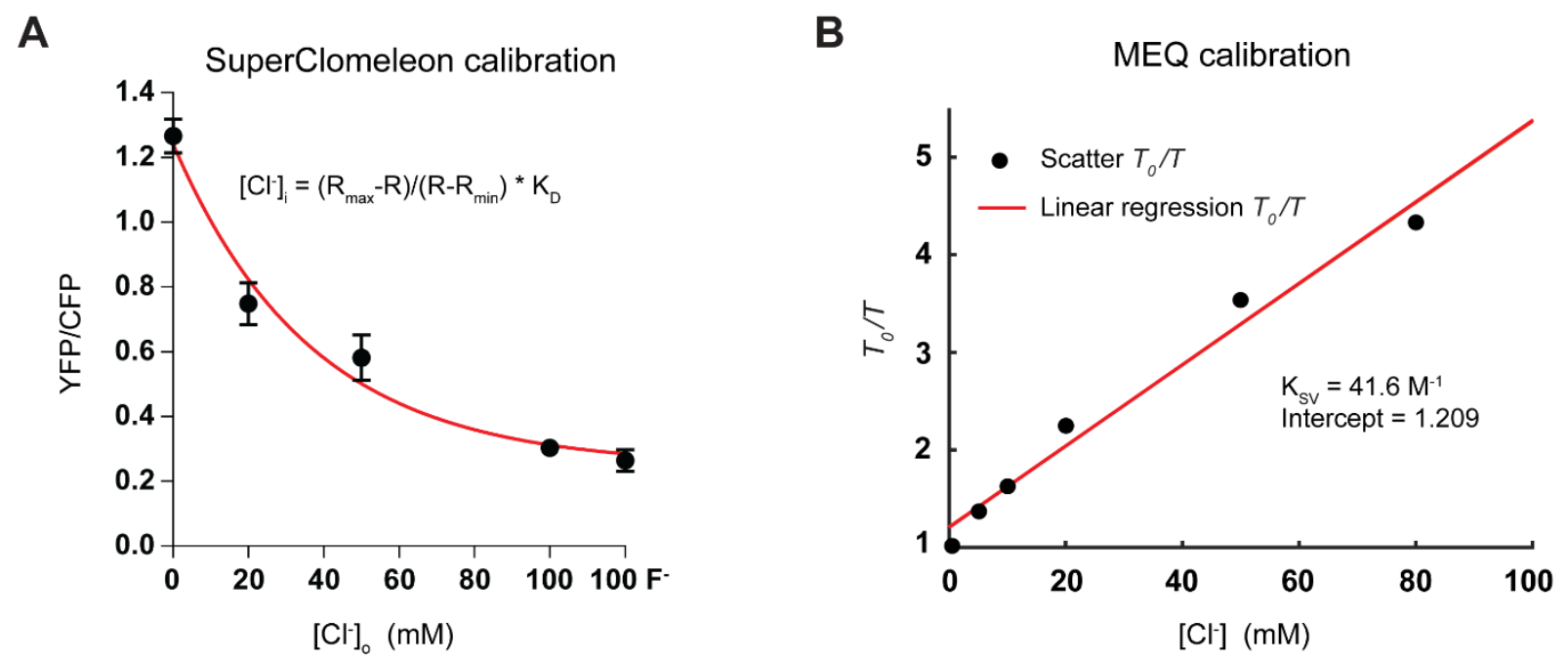

Supplemental Figure 3: Calibration of SuperClomeleon and MEQ. A) SuperClomeleon was calibrated in organotypic slice cultures at different concentrations of $\mathrm{Cl}^{-}$and in the presence of $50 \mu \mathrm{m}$ nigericin and $100 \mu \mathrm{m}$ tributyltin. With single-cell resolution, we calculated $R_{\max }, R_{\min }$ and $K_{D}$ as described in Methods section. Only neurons that responded to different $\mathrm{Cl}^{-}$concentrations in extracellular media $\left(\left[\mathrm{Cl}^{-}\right]_{0}\right)$ were selected for final calculations. The range of values for $\mathrm{R}_{\max }$ measured by two-photon microscopy in different calibration experiments was between 1.240 and 1.777. $\mathrm{R}_{\min }$ ranged between 0.289 and $0.466 . \mathrm{K}_{\mathrm{D}}$ was between 22.31 and $22.99 \mathrm{mM}$. For DualView imaging, $\mathrm{R}_{\max }, \mathrm{R}_{\min }$ were $1.640,0.984$ respectively. B) MEQ was calibrated using Stern-Volmer equation. MEQ was dissolved in the same solution as the internal pipette solution (K-MeSO 4 -based) with different concentrations of $\mathrm{Cl}^{-}$. 


\section{Figure S4}

A

\section{Alexa Fluor 594}

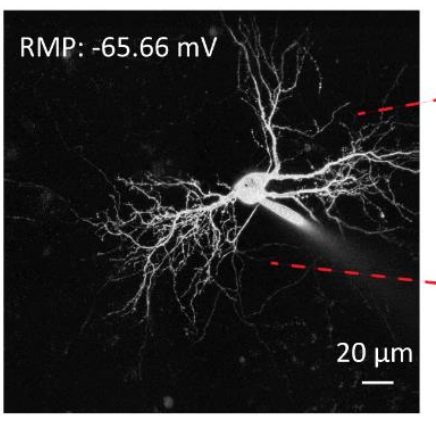

D

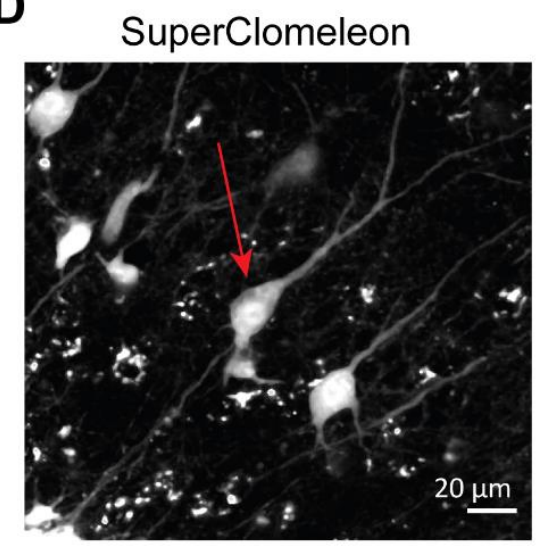

B
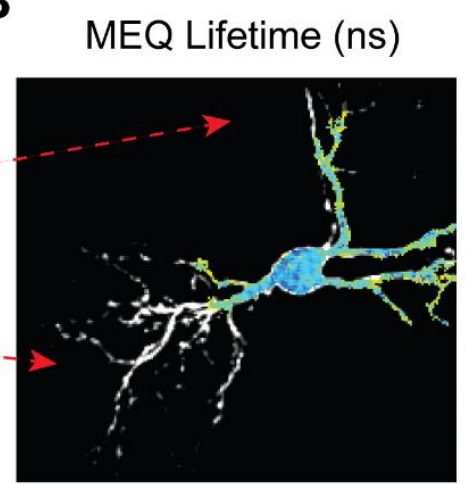

E
C
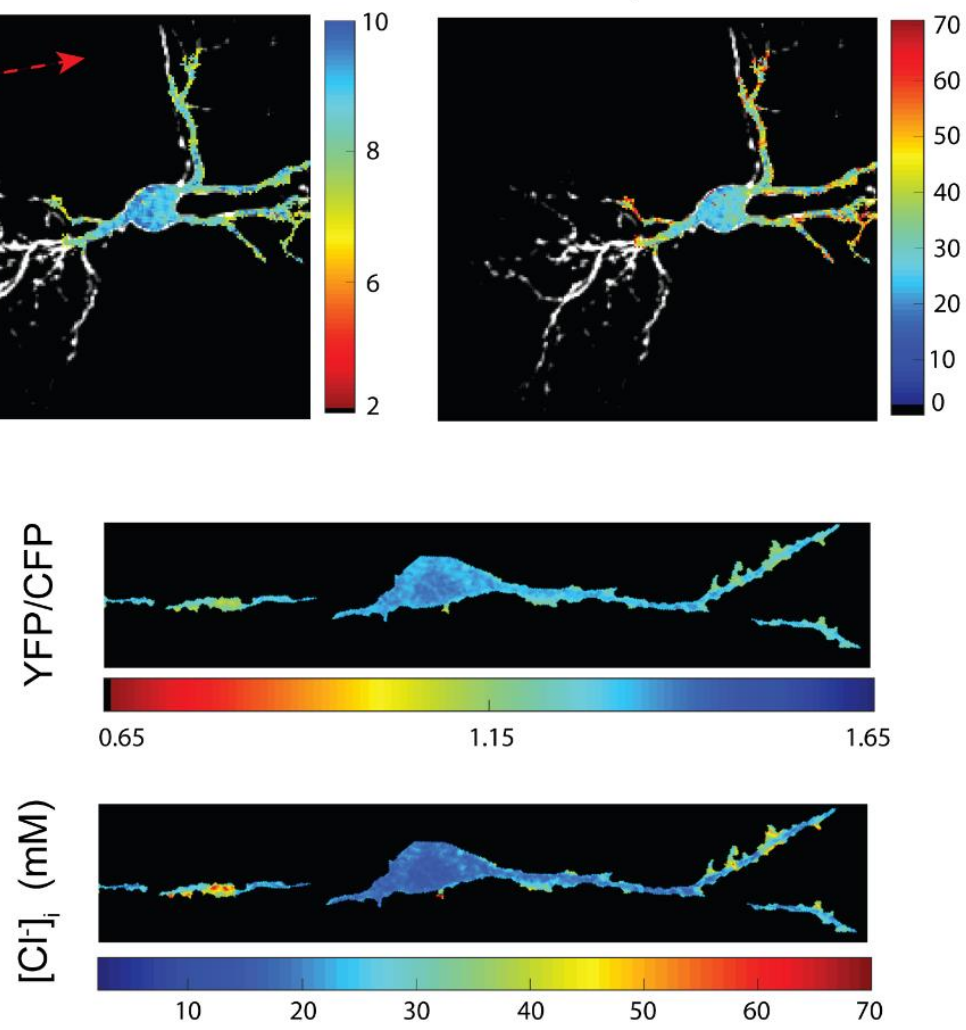

Supplemental Figure 4: Extra examples of $\left[\mathrm{Cl}^{-}\right]_{i}$ two photon and lifetime imaging. A) Two-photon imaging of a pyramidal cell loaded with Alexa Fluor-594. B) Same neuron in A, was also loaded with MEQ to measure lifetime. C) $\left[\mathrm{Cl}^{-}\right]_{\mathrm{i}}$ was calculated based on MEQ calibration shown in Figure S2. D) Two-photon imaging of an interneuron expressing SuperClomeleon. e) The calculated YFP/CFP ratio and $\left[\mathrm{Cl}^{-}\right]_{\mathrm{i}}$. 


\section{Figure S5}

A

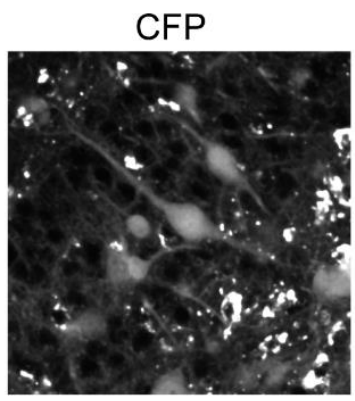

C

$2 \mathrm{D}$ intensity histogram

$256 \times 256$ pixels

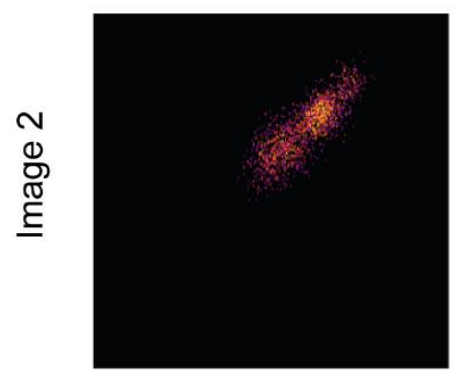

Image 1
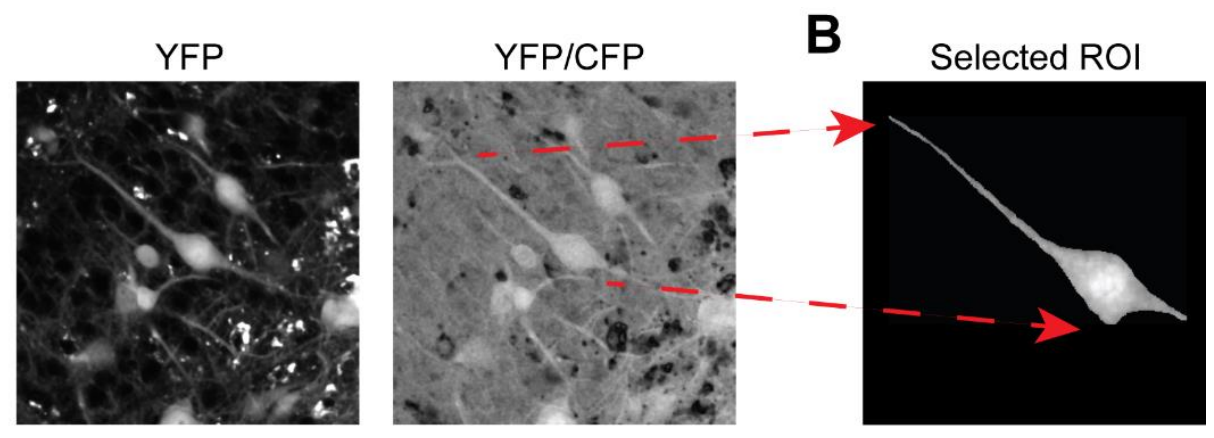

D

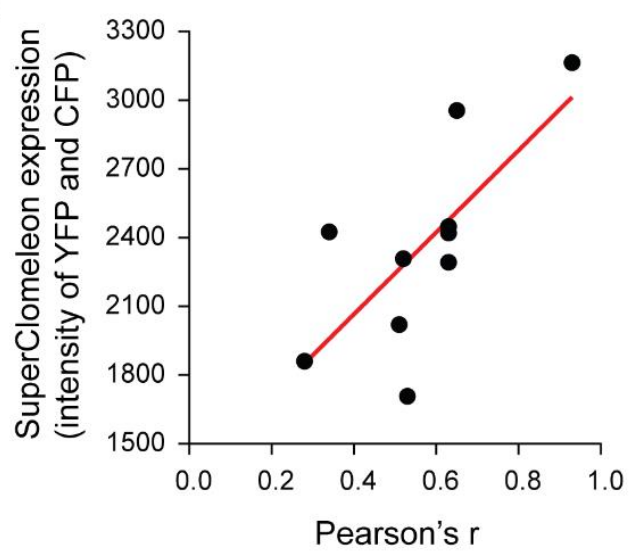

$P=0.01\left(^{*}\right)$

$\mathrm{R}=0.71$

$\mathrm{n}=10$

Supplemental Figure 5: Measuring stability of microdomains. A, B) Colocalization analysis was performed by selecting a region of interest (ROI) and measuring YFP/CFP in each pixel of that ROI. C) Pixel intensity correlation analysis in time-lapsed images was performed by generating 2D intensity histograms and calculating Pearson's r, using Coloc2 Fiji's plugin. D) The observed variability in Pearson's $r$ in different experiments was significantly correlated with expression levels of SuperClomeleon. 


\section{References:}

Donnan, F.G. (1911). The theory of membrane equilibrium in the presence of a non-dialyzable electrolyte. Z Electrochem 17, 572-581.

Procter, H.R. (1914). XXXV.-The equilibrium of dilute hydrochloric acid and gelatin. Journal of the Chemical Society, Transactions 105, 313-327.

Gregor, H.P. (1951). Gibbs-Donnan equilibria in ion exchange resin systems. Journal of the American Chemical Society 73, 642-650.

Manning, G.S. (1978). The molecular theory of polyelectrolyte solutions with applications to the electrostatic properties of polynucleotides. Quarterly reviews of biophysics 11, 179-246.

Gianazza, E., and Righetti, P.G. (1980). Size and charge distribution of macromolecules in living systems. Journal of Chromatography A 193, 1-8.

Marinsky, J.A. (1985). An interpretation of the sensitivity of weakly acidic (basic) polyelectrolyte (cross-linked and linear) equilibria to excess neutral salt. The Journal of Physical Chemistry 89, 5294-5302.

Huguenard, J., and Alger, B. (1986). Whole-cell voltage-clamp study of the fading of GABAactivated currents in acutely dissociated hippocampal neurons. Journal of Neurophysiology 56, $1-18$.

Krapf, R., Berry, C., and Verkman, A. (1988). Estimation of intracellular chloride activity in isolated perfused rabbit proximal convoluted tubules using a fluorescent indicator. Biophysical Journal 53, 955-962.

Romijn, H., De Jong, B., and Ruijter, J. (1988). A procedure for culturing rat neocortex explants in a serum-free nutrient medium. Journal of neuroscience methods 23, 75-83.

Thompson, S.M., Deisz, R.A., and Prince, D.A. (1988). Relative contributions of passive equilibrium and active transport to the distribution of chloride in mammalian cortical neurons. Journal of Neurophysiology 60, 105-124.

Yamamoto, S., Nakanishi, K., and Matsuno, R. (1988). Ion-exchange chromatography of proteins (CRC Press).

Verkman, A., Sellers, M., Chao, A., Leung, T., and Ketcham, R. (1989). Synthesis and characterization of improved chloride-sensitive fluorescent indicators for biological applications. Analytical biochemistry 178, 355-361.

Masuda, T., Dobson, G.P., and Veech, R.L. (1990). The Gibbs-Donnan near-equilibrium system of heart. Journal of Biological Chemistry 265, 20321-20334.

Biwersi, J., and Verkman, A.S. (1991). Cell-permeable fluorescent indicator for cytosolic chloride. Biochemistry 30, 7879-7883.

Stoppini, L., Buchs, P.-A., and Muller, D. (1991). A simple method for organotypic cultures of nervous tissue. Journal of neuroscience methods 37, 173-182.

Biwersi, J., Farah, N., Wang, Y.-X., Ketcham, R., and Verkman, A. (1992). Synthesis of cellimpermeable Cl-sensitive fluorescent indicators with improved sensitivity and optical properties. American Journal of Physiology-Cell Physiology 262, C243-C250.

Marinsky, J. (1993). In Ion Exchange and Solvent Extraction; Marinsky, J. A., Marcus, Y., Eds. (Marcel Dekker Inc.: New York).

Helfferich, F.G. (1995). Ion exchange (Courier Corporation).

Staley, K.J., Soldo, B.L., and Proctor, W.R. (1995). Ionic mechanisms of neuronal excitation by inhibitory GABAA receptors. Science 269, 977-981. 
Gillen, C.M., Brill, S., Payne, J.A., and Forbush, B. (1996). Molecular cloning and functional expression of the $\mathrm{K}-\mathrm{Cl}$ cotransporter from rabbit, rat, and human A new member of the cationchloride cotransporter family. Journal of Biological Chemistry 271, 16237-16244.

Kim, C.-H., and Lisman, J.E. (1999). A role of actin filament in synaptic transmission and longterm potentiation. Journal of Neuroscience 19, 4314-4324.

Pouzat, C., and Marty, A. (1999). Somatic recording of GABAergic autoreceptor current in cerebellar stellate and basket cells. Journal of Neuroscience 19, 1675-1690.

Staley, K.J., and Proctor, W.R. (1999). Modulation of mammalian dendritic GABAA receptor function by the kinetics of Cl- and HCO3- transport. The Journal of physiology 519, 693-712.

DeFazio, R.A., Keros, S., Quick, M.W., and Hablitz, J.J. (2000). Potassium-coupled chloride cotransport controls intracellular chloride in rat neocortical pyramidal neurons. Journal of Neuroscience 20, 8069-8076.

Köhling, R., Vreugdenhil, M., Bracci, E., and Jefferys, J.G. (2000). Ictal epileptiform activity is facilitated by hippocampal GABAA receptor-mediated oscillations. Journal of Neuroscience 20, 6820-6829.

Kuner, T., and Augustine, G.J. (2000). A genetically encoded ratiometric indicator for chloride: capturing chloride transients in cultured hippocampal neurons. Neuron 27, 447-459.

Maccaferri, G., David, J., Roberts, B., Szucs, P., Cottingham, C.A., and Somogyi, P. (2000). Cell surface domain specific postsynaptic currents evoked by identified GABAergic neurones in rat hippocampus in vitro. The Journal of physiology 524, 91-116.

Morton, W. (2000). Ayscough KR, McLaughlin PJ. Latrunculin alters the actin-monomer subunit interface to prevent polymerization Nat Cell Biol 2, 376-378.

Voipio, J., and Kaila, K. (2000). GABAergic excitation and K+-mediated volume transmission in the hippocampus. In Progress in brain research (Elsevier), pp. 329-338.

Barna, B., Kuhnt, U., and Siklós, L. (2001). Chloride distribution in the CA1 region of newborn and adult hippocampus by light microscopic histochemistry. Histochemistry and cell biology 115, 105-116.

Hübner, C.A., Stein, V., Hermans-Borgmeyer, I., Meyer, T., Ballanyi, K., and Jentsch, T.J. (2001). Disruption of KCC2 reveals an essential role of $\mathrm{K}-\mathrm{Cl}$ cotransport already in early synaptic inhibition. Neuron 30, 515-524.

Sola, M., Kneussel, M., Heck, I.S., Betz, H., and Weissenhorn, W. (2001). X-ray crystal structure of the trimeric N-terminal domain of gephyrin. Journal of Biological Chemistry 276, 25294-25301.

Cohen, I., Navarro, V., Clemenceau, S., Baulac, M., and Miles, R. (2002). On the origin of interictal activity in human temporal lobe epilepsy in vitro. Science 298, 1418-1421.

Veech, R.L., Kashiwaya, Y., Gates, D.N., King, M.T., and Clarke, K. (2002). The energetics of ion distribution: the origin of the resting electric potential of cells. IUBMB life 54, 241-252.

Fatin-Rouge, N., Milon, A., Buffle, J., Goulet, R.R., and Tessier, A. (2003). Diffusion and partitioning of solutes in agarose hydrogels: the relative influence of electrostatic and specific interactions. The Journal of Physical Chemistry B 107, 12126-12137.

Gulledge, A.T., and Stuart, G.J. (2003). Excitatory actions of GABA in the cortex. Neuron 37, 299-309.

Stein, V., Hermans-Borgmeyer, I., Jentsch, T.J., and Hübner, C.A. (2004). Expression of the KCl cotransporter KCC2 parallels neuronal maturation and the emergence of low intracellular chloride. Journal of Comparative Neurology 468, 57-64. 
Dzhala, V.I., Talos, D.M., Sdrulla, D.A., Brumback, A.C., Mathews, G.C., Benke, T.A., Delpire, E., Jensen, F.E., and Staley, K.J. (2005). NKCC1 transporter facilitates seizures in the developing brain. Nature medicine 11, 1205-1213.

Jin, X., Huguenard, J.R., and Prince, D.A. (2005). Impaired Cl- extrusion in layer V pyramidal neurons of chronically injured epileptogenic neocortex. Journal of neurophysiology 93, 21172126.

Berglund, K., Schleich, W., Krieger, P., Loo, L.S., Wang, D., Cant, N.B., Feng, G., Augustine, G.J., and Kuner, T. (2006). Imaging synaptic inhibition in transgenic mice expressing the chloride indicator, Clomeleon. Brain cell biology 35, 207-228.

Duebel, J., Haverkamp, S., Schleich, W., Feng, G., Augustine, G.J., Kuner, T., and Euler, T. (2006). Two-photon imaging reveals somatodendritic chloride gradient in retinal ON-type bipolar cells expressing the biosensor Clomeleon. Neuron 49, 81-94.

Sanabria, H., Miller Jr, J.H., Mershin, A., Luduena, R.F., Kolomenski, A.A., Schuessler, H.A., and Nanopoulos, D.V. (2006). Impedance spectroscopy of $\alpha-\beta$ tubulin heterodimer suspensions. Biophysical journal 90, 4644-4650.

Szabadics, J., Varga, C., Molnár, G., Oláh, S., Barzó, P., and Tamás, G. (2006). Excitatory effect of GABAergic axo-axonic cells in cortical microcircuits. Science 311, 233-235.

Brumback, A.C., and Staley, K.J. (2008). Thermodynamic regulation of NKCC1-mediated Clcotransport underlies plasticity of GABAA signaling in neonatal neurons. Journal of Neuroscience 28, 1301-1312.

Janke, C., Rogowski, K., and Van Dijk, J. (2008). Polyglutamylation: a fine-regulator of protein function? EMBO reports 9, 636-641.

Khirug, S., Yamada, J., Afzalov, R., Voipio, J., Khiroug, L., and Kaila, K. (2008). GABAergic depolarization of the axon initial segment in cortical principal neurons is caused by the $\mathrm{Na}-\mathrm{K}-$ $2 \mathrm{Cl}$ cotransporter NKCC1. Journal of Neuroscience 28, 4635-4639.

Romo-Parra, H., Trevino, M., Heinemann, U., and Gutiérrez, R. (2008). GABA actions in hippocampal area CA3 during postnatal development: differential shift from depolarizing to hyperpolarizing in somatic and dendritic compartments. Journal of neurophysiology 99, 15231534.

Tyzio, R., Minlebaev, M., Rheims, S., Ivanov, A., Jorquera, I., Holmes, G.L., Zilberter, Y., BenAri, Y., and Khazipov, R. (2008). Postnatal changes in somatic $\gamma$-aminobutyric acid signalling in the rat hippocampus. European Journal of Neuroscience 27, 2515-2528.

Glykys, J., Dzhala, V.I., Kuchibhotla, K.V., Feng, G., Kuner, T., Augustine, G., Bacskai, B.J., and Staley, K.J. (2009). Differences in cortical versus subcortical GABAergic signaling: a candidate mechanism of electroclinical uncoupling of neonatal seizures. Neuron 63, 657-672.

Sipilä, S.T., Huttu, K., Yamada, J., Afzalov, R., Voipio, J., Blaesse, P., and Kaila, K. (2009). Compensatory enhancement of intrinsic spiking upon NKCC1 disruption in neonatal hippocampus. Journal of Neuroscience 29, 6982-6988.

Dzhala, V.I., Kuchibhotla, K.V., Glykys, J.C., Kahle, K.T., Swiercz, W.B., Feng, G., Kuner, T., Augustine, G.J., Bacskai, B.J., and Staley, K.J. (2010). Progressive NKCC1-dependent neuronal chloride accumulation during neonatal seizures. Journal of Neuroscience 30, 11745-11761.

Földy, C., Lee, S.-H., Morgan, R.J., and Soltesz, I. (2010). Regulation of fast-spiking basket cell synapses by the chloride channel ClC-2. Nature neuroscience 13, 1047.

Lee, H.H., Jurd, R., and Moss, S.J. (2010). Tyrosine phosphorylation regulates the membrane trafficking of the potassium chloride co-transporter KCC2. Molecular and cellular neuroscience 45, 173-179. 
Rinke, I., Artmann, J., and Stein, V. (2010). ClC-2 voltage-gated channels constitute part of the background conductance and assist chloride extrusion. Journal of Neuroscience 30, 4776-4786. Krishnan, G.P., and Bazhenov, M. (2011). Ionic dynamics mediate spontaneous termination of seizures and postictal depression state. Journal of Neuroscience 31, 8870-8882.

Armstrong, C., and Soltesz, I. (2012). Basket cell dichotomy in microcircuit function. The Journal of physiology 590, 683-694.

Beaudoin III, G.M., Lee, S.-H., Singh, D., Yuan, Y., Ng, Y.-G., Reichardt, L.F., and Arikkath, J. (2012). Culturing pyramidal neurons from the early postnatal mouse hippocampus and cortex. Nature protocols 7, 1741.

Dzhala, V., Valeeva, G., Glykys, J., Khazipov, R., and Staley, K. (2012). Traumatic alterations in GABA signaling disrupt hippocampal network activity in the developing brain. Journal of Neuroscience 32, 4017-4031.

Golmohamadi, M., Davis, T.A., and Wilkinson, K.J. (2012). Diffusion and partitioning of cations in an agarose hydrogel. The Journal of Physical Chemistry A 116, 6505-6510.

Bezaire, M.J., and Soltesz, I. (2013). Quantitative assessment of CA1 local circuits: knowledge base for interneuron-pyramidal cell connectivity. Hippocampus 23, 751-785.

Grimley, J.S., Li, L., Wang, W., Wen, L., Beese, L.S., Hellinga, H.W., and Augustine, G.J. (2013). Visualization of synaptic inhibition with an optogenetic sensor developed by cell-free protein engineering automation. Journal of Neuroscience 33, 16297-16309.

Koleske, A.J. (2013). Molecular mechanisms of dendrite stability. Nature Reviews Neuroscience $14,536$.

Arosio, D., and Ratto, G.M. (2014). Twenty years of fluorescence imaging of intracellular chloride. Frontiers in cellular neuroscience 8, 258.

Delpire, E., and Staley, K.J. (2014). Novel determinants of the neuronal Cl- concentration. The Journal of physiology 592, 4099-4114.

Glykys, J., Dzhala, V., Egawa, K., Balena, T., Saponjian, Y., Kuchibhotla, K., Bacskai, B., Kahle, K., Zeuthen, T., and Staley, K. (2014a). Response to Comments on "Local impermeant anions establish the neuronal chloride concentration". Science 345, 1130-1130.

Glykys, J., Dzhala, V., Egawa, K., Balena, T., Saponjian, Y., Kuchibhotla, K., Bacskai, B., Kahle, K., Zeuthen, T., and Staley, K. (2014b). Local impermeant anions establish the neuronal chloride concentration. Science 343, 670-675.

Luhmann, H.J., Kirischuk, S., and Kilb, W. (2014). Comment on "Local impermeant anions establish the neuronal chloride concentration". Science 345, 1130-1130.

Alfonsa, H., Merricks, E., Codadu, N., Cunningham, M., Deisseroth, K., and Racca, C. (2015a). Trevelyan AJ. The contribution of raised intraneuronal chloride to epileptic.

Alfonsa, H., Merricks, E.M., Codadu, N.K., Cunningham, M.O., Deisseroth, K., Racca, C., and Trevelyan, A.J. (2015b). The contribution of raised intraneuronal chloride to epileptic network activity. Journal of Neuroscience 35, 7715-7726.

Astorga, G., Bao, J., Marty, A., Augustine, G.J., Franconville, R., Jalil, A., Bradley, J., and Llano, I. (2015). An excitatory GABA loop operating in vivo. Frontiers in cellular neuroscience 9, 275.

Kahle, K.T., Khanna, A.R., Alper, S.L., Adragna, N.C., Lauf, P.K., Sun, D., and Delpire, E. (2015). K-Cl cotransporters, cell volume homeostasis, and neurological disease. Trends in molecular medicine 21, 513-523.

Morawski, M., Reinert, T., Meyer-Klaucke, W., Wagner, F.E., Tröger, W., Reinert, A., Jäger, C., Brückner, G., and Arendt, T. (2015). Ion exchanger in the brain: quantitative analysis of 
perineuronally fixed anionic binding sites suggests diffusion barriers with ion sorting properties. Scientific reports 5, 16471.

Silayeva, L., Deeb, T.Z., Hines, R.M., Kelley, M.R., Munoz, M.B., Lee, H.H., Brandon, N.J., Dunlop, J., Maguire, J., and Davies, P.A. (2015). KCC2 activity is critical in limiting the onset and severity of status epilepticus. Proceedings of the National Academy of Sciences 112, 35233528.

Berglund, K., Wen, L., Dunbar, R.L., Feng, G., and Augustine, G.J. (2016). Optogenetic visualization of presynaptic tonic inhibition of cerebellar parallel fibers. Journal of Neuroscience 36, 5709-5723.

Buchin, A., Chizhov, A., Huberfeld, G., Miles, R., and Gutkin, B.S. (2016). Reduced efficacy of the KCC2 cotransporter promotes epileptic oscillations in a subiculum network model. Journal of Neuroscience 36, 11619-11633.

Doyon, N., Vinay, L., Prescott, S.A., and De Koninck, Y. (2016). Chloride regulation: a dynamic equilibrium crucial for synaptic inhibition. Neuron 89, 1157-1172.

Khazipov, R. (2016). GABAergic synchronization in epilepsy. Cold Spring Harbor perspectives in medicine 6, a022764.

Rahmati, N., Veloz, M.F.V., Xu, J., Barone, S., Hamida, N.R.B., Schonewille, M., Hoebeek, F.E., Soleimani, M., and De Zeeuw, C.I. (2016). SLC26A11 (KBAT) in Purkinje cells is critical for inhibitory transmission and contributes to locomotor coordination. eNeuro 3.

Spruston, N., Stuart, G., and Häusser, M. (2016). Principles of dendritic integration. Dendrites $351,597$.

Untiet, V., Moeller, L.M., Ibarra-Soria, X., Sánchez-Andrade, G., Stricker, M., Neuhaus, E.M., Logan, D.W., Gensch, T., and Spehr, M. (2016). Elevated cytosolic Cl- concentrations in dendritic knobs of mouse vomeronasal sensory neurons. Chemical senses 41, 669-676.

Glykys, J., Dzhala, V., Egawa, K., Kahle, K.T., Delpire, E., and Staley, K. (2017). Chloride dysregulation, seizures, and cerebral edema: a relationship with therapeutic potential. Trends in neurosciences 40, 276-294.

Grienberger, C., Milstein, A.D., Bittner, K.C., Romani, S., and Magee, J.C. (2017). Inhibitory suppression of heterogeneously tuned excitation enhances spatial coding in CA1 place cells. Nature neuroscience 20, 417.

Heubl, M., Zhang, J., Pressey, J.C., Al Awabdh, S., Renner, M., Gomez-Castro, F., Moutkine, I., Eugène, E., Russeau, M., and Kahle, K.T. (2017). GABA A receptor dependent synaptic inhibition rapidly tunes $\mathrm{KCC} 2$ activity via the $\mathrm{Cl}-$-sensitive $\mathrm{WNK} 1$ kinase. Nature communications 8, 1776.

Raimondo, J.V., Richards, B.A., and Woodin, M.A. (2017). Neuronal chloride and excitabilitythe big impact of small changes. Current opinion in neurobiology 43, 35-42.

Sato, S.S., Artoni, P., Landi, S., Cozzolino, O., Parra, R., Pracucci, E., Trovato, F., Szczurkowska, J., Luin, S., and Arosio, D., Fabio, B., Cancedda, L., Kaila, K., and Ratto, GM. (2017). Simultaneous two-photon imaging of intracellular chloride concentration and $\mathrm{pH}$ in mouse pyramidal neurons in vivo. Proceedings of the National Academy of Sciences 114, E8770-E8779.

Savtchenko, L.P., Poo, M.M., and Rusakov, D.A. (2017). Electrodiffusion phenomena in neuroscience: a neglected companion. Nature reviews Neuroscience 18, 598.

Zorrilla de San Martin, J., Trigo, F.F., and Kawaguchi, S.y. (2017). Axonal GABAA receptors depolarize presynaptic terminals and facilitate transmitter release in cerebellar Purkinje cells. The Journal of physiology 595, 7477-7493. 
Boffi, J.C., Knabbe, J., Kaiser, M., and Kuner, T. (2018). KCC2-dependent Steady-state Intracellular Chloride Concentration and $\mathrm{pH}$ in Cortical Layer 2/3 Neurons of Anesthetized and Awake Mice. Frontiers in cellular neuroscience 12, 7.

Düsterwald, K.M., Currin, C.B., Burman, R.J., Akerman, C.J., Kay, A.R., and Raimondo, J.V. (2018). Biophysical models reveal the relative importance of transporter proteins and impermeant anions in chloride homeostasis. Elife 7, e39575.

Gut, G., Herrmann, M.D., and Pelkmans, L. (2018). Multiplexed protein maps link subcellular organization to cellular states. Science 361, eaar7042.

Schmidt, T., Ghaffarian, N., Philippot, C., Seifert, G., Steinhäuser, C., Pape, H.-C., and Blaesse, P. (2018). Differential regulation of chloride homeostasis and GABAergic transmission in the thalamus. Scientific reports 8, 13929.

Burman, R.J., Selfe, J.S., Lee, H.J., van den Berg, M., Calin, A., Codadu, N.K., Wright, R., Newey, S.E., Parrish, R.R., and Katz, A.A. (2019). Excitatory GABAergic signalling is associated with acquired benzodiazepine resistance in status epilepticus. bioRxiv, 478594.

Garand, D., Mahadevan, V., and Woodin, M.A. (2019). Ionotropic and metabotropic kainate receptor signalling regulates $\mathrm{Cl}-$ homeostasis and GABAergic inhibition. The Journal of physiology 597, 1677-1690.

Glykys, J., Duquette, E., Rahmati, N., Duquette, K., and Staley, K. (2019). Mannitol decreases neocortical epileptiform activity during early brain development via cotransport of chloride and water. Neurobiology of disease 125, 163-175.

Chen, X., Wu, X., Wu, H., and Zhang, M. (2020). Phase separation at the synapse. Nature Neuroscience, 1-10. 